\title{
Development of Cross-Orientation Suppression and Size Tuning and the Role of Experience
}

\author{
Marjena Popović, ${ }^{1,2,3}$ Andrea K. Stacy, ${ }^{1,2}$ Mihwa Kang, ${ }^{1}{ }^{-R o s h a n ~ N a n u, ~}{ }^{1,2}$ Charlotte E. Oettgen, ${ }^{1,4}$ Derek L. Wise, ${ }^{1,2}$ \\ József Fiser, ${ }^{2,3,5}$ and (DStephen D. Van Hooser ${ }^{1,2,3}$ \\ ${ }^{1}$ Department of Biology, ${ }^{2}$ Volen Center for Complex Systems, ${ }^{3}$ Sloan-Swartz Center for Theoretical Neurobiology, Brandeis University, Waltham, \\ Massachusetts 02454, ${ }^{4}$ Department of Biology, Bates College, Lewiston, Maine 04240, and ${ }^{5}$ Department of Cognitive Sciences, Central European University, \\ 1051, Budapest, Hungary
}

Many sensory neural circuits exhibit response normalization, which occurs when the response of a neuron to a combination of multiple stimuli is less than the sum of the responses to the individual stimuli presented alone. In the visual cortex, normalization takes the forms of cross-orientation suppression and surround suppression. At the onset of visual experience, visual circuits are partially developed and exhibit some mature features such as orientation selectivity, but it is unknown whether cross-orientation suppression is present at the onset of visual experience or requires visual experience for its emergence. We characterized the development of normalization and its dependence on visual experience in female ferrets. Visual experience was varied across the following three conditions: typical rearing, dark rearing, and dark rearing with daily exposure to simple sinusoidal gratings ( $14-16 \mathrm{~h}$ total). Cross-orientation suppression and surround suppression were noted in the earliest observations, and did not vary considerably with experience. We also observed evidence of continued maturation of receptive field properties in the second month of visual experience: substantial length summation was observed only in the oldest animals (postnatal day 90); evoked firing rates were greatly increased in older animals; and direction selectivity required experience, but declined slightly in older animals. These results constrain the space of possible circuit implementations of these features.

Key words: development; divisive normalization; nature; nurture; sensory cortex; vision

\section{Significance Statement}

The development of the brain depends on both nature-factors that are independent of the experience of an individual animaland nurture-factors that depend on experience. While orientation selectivity, one of the major response properties of neurons in visual cortex, is already present at the onset of visual experience, it is unknown whether response properties that depend on interactions among multiple stimuli develop without experience. We find that the properties of cross-orientation suppression and surround suppression are present at eye opening, and do not depend on visual experience. Our results are consistent with the idea that a majority of the basic properties of sensory neurons in primary visual cortex are derived independent of the experience of an individual animal.

\section{Introduction}

One of the most ubiquitous features of sensory receptive fields across species, modalities, and cortical hierarchies is the property

Received Oct. 5, 2017; revised Dec. 19, 2017; accepted Jan. 22, 2018.

Author contributions: M.P., J.F., and S.D.V.H. designed research; M.P., A.K.S., M.K., R.N., C.E.O., and D.L.W. performed research; M.P. and S.D.V.H. analyzed data; M.P. and S.D.V.H. wrote the paper.

This work was funded by the National Science Foundation Division of Integrative Organismal Systems Grant 1120938 (to M.P., J.F., and S.D.V.H.), National Institutes of Health, Eye Institute 022122 (to S.D.V.H.), and by a Hoffman Research Fellowship from Bates College (to C.E.0.). We thank Alexandra Hempel, Victoria Drumm, David Landesman, George Popa, Tudor Dragoi, Rebecca Panitch, and Lizbeth Lueck, for help with animal husbandry; and members of the Van Hooser laboratory for comments.

The authors declare no competing financial interests.

Correspondence should be addressed to Stephen D. Van Hooser, Brandeis University, 415 South Street, MS008, Waltham, MA 02454.E-mail: vanhooser@brandeis.edu.

DOI:10.1523/JNEUROSCI.2886-17.2018

Copyright $\odot 2018$ the authors $\quad 0270-6474 / 18 / 382656-15 \$ 15.00 / 0$ of divisive normalization: cells exhibit responses to combinations of stimuli that are less than the sum of the responses to the individual stimuli (Heeger, 1992; Carandini et al., 1997; Tolhurst and Heeger, 1997; Simoncelli and Heeger, 1998; Britten and Heuer, 1999; Reynolds and Heeger, 2009; Olsen et al., 2010; Ohshiro et al., 2011; Ruff et al., 2016). In the primary visual cortex, the most studied form of normalization is cross-orientation suppression, which occurs when the response of a neuron to an optimally oriented grating stimulus is suppressed by a superimposed orthogonal grating (plaid stimulus) that does not, by itself, elicit a response (Adelson and Movshon, 1982; Morrone et al., 1982; Morrone et al., 1987; DeAngelis et al., 1992). In addition, some models also posit that other contextual interactions — such as size tuningare simply forms of normalization (Rubin et al., 2015). Size tuning includes surround suppression (Hubel and Wiesel, 1965; 
Gilbert, 1977; Bolz and Gilbert, 1986; DeAngelis et al., 1994) and length summation (Bolz and Gilbert, 1989; Chisum et al., 2003; Van Hooser et al., 2006). Despite the importance of normalization in sensory computation, it remains unknown whether the development of cross-orientation suppression requires sensory experience or, rather, is formed without experience. Behavioral and electrophysiological evidence of surround suppression has been observed in the youngest macaque monkeys studied (Zhang et al., 2005; Li et al., 2013), but it remains unclear whether these results hold in other species.

The proper development of most neural circuits is contingent on both experience-independent and experience-dependent factors. Some response properties of sensory neurons are present before sensory experience. At the onset of visual experience, neurons in carnivore $\mathrm{V} 1$ already exhibit tuning for stimulus orientation, spatial frequency (SF), and temporal frequency (TF), and this tuning is elaborated or altered by experience-dependent processes (Chapman and Stryker, 1993; White et al., 2001; Li et al., 2006b). Other response properties require experience for their expression. For example, direction selectivity is very weak at the onset of visual experience, and develops rapidly when the ferret experiences moving visual stimuli (Li et al., 2006b, 2008; Van Hooser et al., 2012; Smith et al., 2015).

To study the influence of experience on cross-orientation suppression and size tuning, we compared visual receptive field properties in dark-reared animals and typically reared animals at several ages. Additionally, we exposed some dark-reared animals to several hours of viewing artificial stimuli-large gratings of single orientations. These impoverished stimuli lacked the simultaneous presentation of multiple orientations, spatial and temporal frequencies, as well as variation in size typical of natural images. This allowed us to further explore the influence of the quality of visual experience on the emergence of cross-orientation suppression and size tuning.

We found that cross-orientation suppression and surround suppression were present in both dark-reared animals and experienced animals, although the magnitude of this tuning varied slightly with experience and age. Cross-orientation suppression and surround suppression in animals whose experience was limited to large gratings of single orientations did not differ from that of typically reared animals, suggesting that experience is not critical for the emergence of these properties.

Finally, we uncovered unexpected evidence that basic visual cortical response properties continue to mature even after a month of visual experience. In typically reared ferrets, direction selectivity reached a peak approximately a week after eye opening and was reduced later, suggesting that some properties change with age in a nonmonotonic fashion. In addition, evoked firing rates and length summation increased substantially during the second month of visual experience. These changes occurred after the outgrowth of the long-range horizontal connections within visual cortex (Durack and Katz, 1996; Ruthazer and Stryker, 1996; White et al., 2001), but closely follow the growth of synaptic density to its peak at $\sim 90 \mathrm{~d}$ of age (Erisir and Harris, 2003; White and Fitzpatrick, 2007).

\section{Materials and Methods}

All experimental procedures were approved by the Brandeis University Animal Care and Use Committee and performed in compliance with National Institutes of Health guidelines.

\section{Experimental design and statistical analysis}

Female sable ferrets (Mustela putorius furo) used in the experiment were split into five study groups (Fig. 1). Female animals were chosen because it is stressful to the animals to house sexually mature animals of both sexes in the same space, and jills (female mothers) were necessary to care for the kits (young). The groups were as follows.

Dark-reared animals. The animals $(n=5)$ were reared with three to five littermates and their jill in complete darkness starting 1-3 d before eye opening [postnatal day 27 (P27) to P30] until the experiment at age $\mathrm{P} 40$ to $\mathrm{P} 42$. The kits were nursed by their jill until spontaneous weaning occurred; water and soft diet were available ad libitum. These animals were also used in an unrelated study; we took advantage of the opportunity to make additional discoveries with animals that were being initially studied for other purposes. As a part of this unrelated experiment, at P30 (with eyes still closed) the ferrets were implanted with chronic microelectrode arrays in left V1, and at P33 and P37 they were subject to two 80 -min-long, head-fixed recording sessions. Stimuli consisted of $20 \mathrm{~min}$ of a grayscale natural movie, 20 min of drifting gratings, 20 min of block noise, and 20 min of a dark screen (Berkes et al., 2011). While it would have been ideal (for the study discussed here) to have had access to animals that did not include this procedure, our previous research has found that $<3 \mathrm{~h}$ of visual experience does not cause a substantial increase in direction selectivity, so we did not expect substantial influence of the experience that occurs during these measurements (Clemens et al., 2012; Roy et al., 2016; Ritter et al., 2017). During the postoperative recovery, they were additionally fed milk replacement (KMR, PetAg) with a syringe. The need for additional syringe feeding was not related to dark rearing - it did not differ from that observed in typically reared ferrets of corresponding age after surgery. Ferrets were observed, and their weight was monitored daily using night vision goggles with an infrared light source. No effects of dark rearing on the general health and behavior of the animals were observed.

Dark-reared, trained animals. The animals $(n=7)$ were reared with three to five littermates and their jill in complete darkness starting 1-3 d before eye opening (P27 to P30) until the experiment at age P40 to P42. As a part of the previously described unrelated experiment, at P30 they were implanted with chronic microelectrode arrays in left V1 and had headposts affixed, and at P33 and P37 they were subject to two 80-minlong recording sessions. Between P33 and P37, the ferrets were exposed to controlled visual experience. Awake ferrets were head fixed and placed in front of a screen inside a dark box for two 1.5-h-long sessions daily with a $1.5 \mathrm{~h}$ break in between the sessions. The sessions added to a total of $14-16 \mathrm{~h}$ of stimulation. The training stimuli consisted of bidirectionally drifting sinusoidal gratings of varying orientation (from horizontal to vertical in $22.5^{\circ}$ steps) at $0.1 \mathrm{cycle} /{ }^{\circ}$ spatial frequency, $4 \mathrm{~Hz}$ temporal frequency, and $100 \%$ contrast in 20 min blocks separated with 10 min of mean luminance. Other than the daily training sessions, the rearing conditions for ferrets in this experimental group were identical to those in the dark-reared group. Efforts were made to keep the dark-reared ferret kits awake during the period of visual stimulation (gentle tapping or gentle hand clapping), although these very young animals frequently dozed for several minutes during the visual exposure.

Typically reared, P40 animals. The animals $(n=8)$ were reared with three to five littermates and a jill in a $12 \mathrm{~h}$ light/dark cycle environment until the experiment at age P40 to P42. Just like dark-reared animals, ferrets were housed in a modified rabbit cage $(61 \mathrm{~cm}$ wide $\times 61 \mathrm{~cm}$ long $\times 38 \mathrm{~cm}$ high). One side of the cage was mostly open with only thin bars $(3 \mathrm{~mm}$, spaced every $2.5 \mathrm{~cm}$ ). All other sides had two rows of 0.8 $\mathrm{cm}$-wide by $5-\mathrm{cm}$-tall slats, spaced every $3 \mathrm{~cm}$. Animals had a hammock to use as a nest and as entertainment. As a part of the previously described unrelated experiment, at P30 they were implanted with chronic microelectrode arrays in left V1 and had headposts affixed, and at P33 and P37 they were subject to two 80-min-long recording sessions.

Typically reared, $P 60$ animals. The animals $(n=4)$ were reared in a $12 \mathrm{~h}$ light/dark cycle environment until the experiment at age P59 to P66.

Typically reared, P90. The animals $(n=6)$ were reared in a $12 \mathrm{~h}$ light/dark cycle environment until the experiment at age P90 to P92.

A full description of statistical analysis and a table of all animals and cells examined follows the Data analysis subsection. 


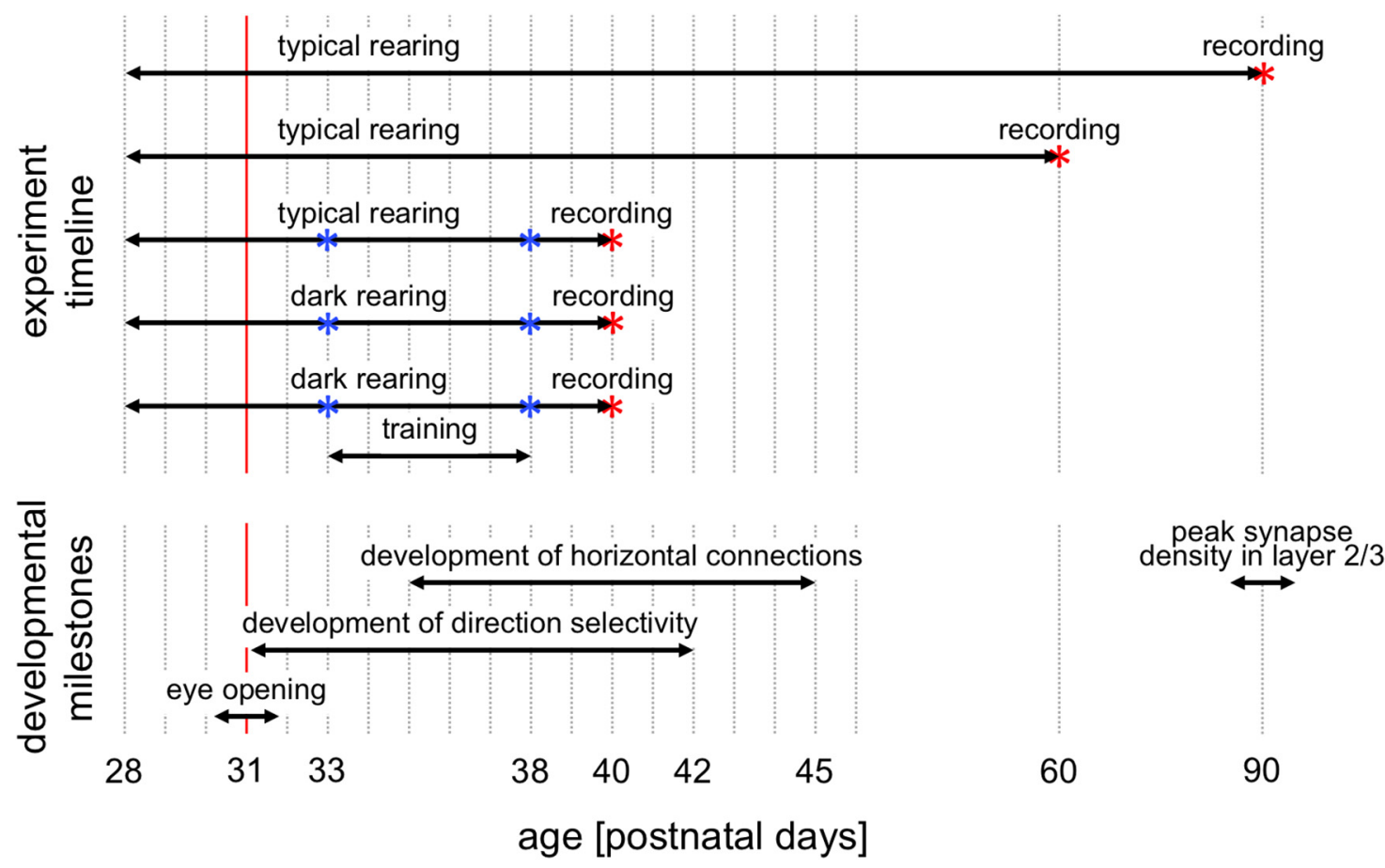

Figure 1. Experimental groups. We studied the development of receptive field properties while varying visual experience and age. We reared three groups of animals until approximately P40 (see Materials and Methods) according to different protocols. One group (typically reared, P40) was provided $12 \mathrm{~h}$ of normal light each day. Another group (dark-reared, P40) was raised in darkness from P28 ( 3-5 d before normal eye opening) and had very impoverished visual experience. A third group (dark-reared and trained, P40) was raised in the dark from P28 but was provided with 14-16 total hours of experience with simple sinusoidal grating stimuli over several sessions. These groups were compared with animals with 1 month of typical visual experience (typically reared, P60) and $\sim 2$ months of visual experience (typically reared, P90). Red stars denote the times of the recordings. Blue stars denote when the animals were exposed to 80 -min-long visual stimulation in an unrelated experiment.

\section{Survival surgery}

All the ferrets in the dark-reared, dark-reared trained, and typically reared $\sim$ P40 group were also used in an unrelated chronic recording experiment. For this experiment, ferrets had a $2 \times 8$ microwire electrode array implanted into V1 in the left hemisphere at age P30 while their eyes were still closed. Immediately before the surgery and up to $48 \mathrm{~h}$ after surgery, ferrets were intramuscularly administered analgesic ketoprofen $(1 \mathrm{mg} / \mathrm{kg})$ and antibiotic penicillin $(27 \mathrm{mg} / \mathrm{kg})$, and orally administered analgesic tramadol $(2 \mathrm{mg} / \mathrm{kg})$. During the surgery, ferrets were anesthetized with an intramuscular injection of a ketamine-xylazine cocktail (20 and $2 \mathrm{mg} / \mathrm{kg}$, respectively) and were given atropine $(0.04 \mathrm{mg} / \mathrm{kg})$ to reduce secretions. Surgical margins were infused with $0.2 \mathrm{ml}$ of the local analgesic bupivacaine. At the end of surgery, anesthesia was reversed using the xylazine antidote yohimbine $(0.5 \mathrm{mg} / \mathrm{kg})$. Importantly, the last dose of analgesics was given $24 \mathrm{~h}$ before the start of training. Body temperature was maintained at $37^{\circ} \mathrm{C}$ using a thermostatically controlled heating pad, heart rate was continuously monitored, and hydration was maintained throughout by subcutaneous injections of lactated Ringer's solution $(3 \mathrm{ml} / \mathrm{kg} / \mathrm{h})$. The cranium was exposed, and a $4 \times 4 \mathrm{~mm}$ craniotomy was made over V1. A durotomy was performed with a 31 gauge needle before placing the electrode array into the brain. The brain was sealed with a low-toxicity silicone elastomere (Kwik-Cast, World Precision Instruments), and the electrode and headpost were affixed to the skull using six skull screws and a light-cured dental composite (Flow-It ALC, Pentron). After the animals were ambulatory, they were transferred back to the cage with their littermates and jill.

\section{Acute surgical procedures}

Ferrets were sedated with ketamine $(20 \mathrm{mg} / \mathrm{kg}, \mathrm{i} . \mathrm{m}$.). Atropine $(0.16-0.8$ $\mathrm{mg} / \mathrm{kg}$, i.m.) was administered to prevent bradycardia and reduce bronchial and salivary secretion, and dexamethasone $(0.5 \mathrm{mg} / \mathrm{kg}$, i.m.) administered to reduce inflammation and swelling. The animal was deeply anesthetized with a mixture of isoflurane, oxygen, and nitrous oxide through a face mask while a tracheotomy was performed. Once the tracheotomy was completed, the animal was ventilated with $1-2 \%$ isoflu- rane in a 2:1 mixture of nitrous oxide and oxygen. A cannula was inserted into the intraperitoneal cavity for delivery of $5 \%$ dextrose in lactated Ringer's solution $(3 \mathrm{ml} / \mathrm{kg} / \mathrm{h})$. Body temperature was maintained at $37^{\circ} \mathrm{C}$ using a thermostatically controlled heating pad. End-tidal $\mathrm{CO}_{2}$ levels and respiration rate were monitored and kept within the appropriate physiological range $(3.5-4 \%)$. The animal was held in place by a custom stereotaxic frame. All wound margins were infused with bupivacaine. Silicone oil was placed on the eyes to prevent damage to the cornea. A $4 \times$ $4 \mathrm{~mm}$ craniotomy was made over V1 in the right hemisphere, and the dura was removed with a 31 gauge needle.

Before the start of recording, ferrets were paralyzed using a neuromuscular blocker (gallamine triethiodide $10-30 \mathrm{mg} / \mathrm{h} / \mathrm{kg}$ ), delivered through the intraperitoneal cannula, to suppress spontaneous eye movements. The nitrous oxide/oxygen ratio was adjusted to 1:1. Adequate anesthesia was maintained by continuously monitoring the EKG of the animals and adjusting the isoflurane concentration. At the conclusion of the experiment, the animal was killed and transcardially perfused to retrieve the brain for histology.

\section{Electrophysiological recordings}

Carbon fiber electrodes (Carbostar-1, Kation Scientific) were used for all recordings. The signal was amplified using the RHD2000 amplifying/ digitizing chip and USB interface board (Intan Technologies) and acquired and clustered using a Micro1401 acquisition board and Spike2 software (Cambridge Electronic Design). Spike sorting was performed manually using Spike 2 software.

An electrode was inserted into the brain using a Sutter Instruments MP-285 manipulator. To reduce sampling bias, we recorded from any site that had a signal-to-noise ratio sufficient for isolation and had a response that appeared to be modulated by the presentation of drifting gratings. Data are reported from all units that are responsive enough to be included in analysis (see below). After finishing the recording at one site, the electrode was lowered at least $40 \mu \mathrm{m}$ before attempting to identify a suitable subsequent recording site. The experiment was concluded 
Table 1. Number of cells analyzed per condition

\begin{tabular}{|c|c|c|c|c|c|}
\hline & Dark-reared P40 & Dark-reared trained P40 & Typically reared P40 & Typically reared P60 & Typically reared P90 \\
\hline Ages & $2 \times 40,3 \times 42$ & $1 \times 39,2 \times 40,4 \times 42$ & $2 \times 40,2 \times 41,4 \times 42$ & $2 \times 59,1 \times 61,1 \times 66$ & $4 \times 90,1 \times 91,1 \times 92$ \\
\hline Animals & 5 & 7 & 8 & 4 & 6 \\
\hline Cells & 71 & 77 & 79 & 45 & 63 \\
\hline \multicolumn{6}{|l|}{ Cells included } \\
\hline DS & 50 & 54 & 47 & 29 & 49 \\
\hline SF & 66 & 73 & 53 & 43 & 59 \\
\hline TF & 69 & 71 & 55 & 42 & 55 \\
\hline Contrast & 67 & 70 & 40 & 39 & 58 \\
\hline Size & 44 & 37 & 31 & 32 & 45 \\
\hline Cross-orientation suppression & 54 & 52 & 55 & 40 & 60 \\
\hline
\end{tabular}

Values are the number of cells. DS, Direction selectivity.

once white matter was reached or once the physiological indicators of the animal became unstable.

\section{Visual stimulation}

Visual stimuli were created in MATLAB (MathWorks) using the Psychophysics Toolbox (Brainard, 1997; Pelli, 1997) and displayed on a 21 inch flat face CRT monitor (GDM-520, Sony) with a resolution of $800 \times 600$ and a refresh rate of $100 \mathrm{~Hz}$. The monitor was positioned $20 \mathrm{~cm}$ away from the eyes of the animals, such that it was subtending $63^{\circ} \times 63^{\circ}$ of visual angle. For each unit we isolated, we first determined the ocular dominance and occluded the nondominant eye. We then used circular patches of drifting sinusoidal gratings of varying sizes to manually map receptive fields. We moved the monitor to accommodate all eccentricities without varying the distance of the monitor from the animal.

\section{Immunohistochemistry}

Upon completion of each experiment, electrolytic lesions were made at the final recording site and at $\sim 300 \mu \mathrm{m}$ from the surface of the cortex to enable the reconstruction of the electrode track. Following a transcardial perfusion, the brain was placed in $4 \%$ paraformaldehyde in $0.1 \mathrm{~m}$ PBS at $4^{\circ} \mathrm{C}$ for $24 \mathrm{~h}$, and then moved to $10 \%$ sucrose in PBS at $4^{\circ} \mathrm{C}$ for $24-48 \mathrm{~h}$, followed by $30 \%$ sucrose in PBS at $4^{\circ} \mathrm{C}$ for $24-48 \mathrm{~h}$.

\section{Data analysis}

We recorded from a total of $335 \mathrm{~V} 1$ neurons of 30 female sable ferrets in five experimental conditions. Cells with a response rate of $<2$ spikes/s were excluded during analysis, but were still recorded from if they appeared to be modulated by the stimuli during the experiment. The actual number of cells included in the analysis varied across conditions (Table 1). Additional exclusion criteria for specific analyses are discussed in separate sections below.

\section{Orientation and direction tuning}

We characterized the orientation and direction selectivity of all cells using bidirectionally drifting sinusoidal grating stimuli of varying direction $\left(22.5^{\circ}\right.$ steps $)$ at 0.1 cycle $/{ }^{\circ}$ spatial frequency, $4 \mathrm{~Hz}$ temporal frequency, and $100 \%$ contrast. Orientation/direction tuning curves were fit with a mixture of two Gaussians in circular space, forced to peak $180^{\circ}$ apart and to have the same width (Carandini and Ferster, 2000) as follows:

$$
R(\theta)=R_{0}+R_{\text {pref }} e^{-\left\langle\theta-\theta_{\text {pref }}\right\rangle^{2}} / 2 \sigma^{2}+R_{\text {pref }+180} e^{-\left\langle\theta-\theta_{\text {pref }}+180\right\rangle^{2}} / 2 \sigma^{2},
$$

where $\theta$ is the stimulus direction in circular space $\left(0^{\circ}\right.$ to $\left.360^{\circ}\right), R_{0}$ is a constant offset, $\theta_{\text {pref }}$ is the preferred orientation, the tuning width $\left(R_{\text {pref }}\right)$ is the increment above offset to the preferred direction, $\left(R_{\text {pref }}+180\right)$ is the increment above offset to the opposite direction, and the tuning width (half-width at half-height) is given by $\sigma \sqrt{\log (4)}$.

To ensure good fitting, we constrained the fitting parameters as follows: $\sigma \geq \alpha / 2$, where $\alpha$ is the stimulus angle step size $\left(22.5^{\circ}\right) ;-R_{\max } \leq R_{0} \leq$ $R_{\max }$, where $R_{\max }$ is the highest observed response for any stimulus; and $0 \leq R_{\text {pref, }} R_{\text {pref }}+180 \leq 3 R_{\max }$. We initiated iterative fitting at parameter values expected to produce a good fit as follows: $\theta_{\text {pref }}=\theta R_{\max } ; R_{\text {pref }}=$ $R_{\text {pref }}+180=R_{\text {max }} ; R_{0}=0$. We performed fitting for $\sigma \equiv\left(\alpha / 2, \alpha, 40^{\circ}\right.$, $60^{\circ}, 90^{\circ}$ ) and selected the fit with the lowest least squared error. Finally, we eliminated from further analysis cells that did not exhibit significant orientation tuning as quantified by Hotelling's T2 test performed on orientation vector for each trial. This was done because the fitting method has been shown to produce large errors in $\theta_{\text {pref }}$ at low orientation index values (Mazurek et al., 2014).

Orientation selectivity was quantified using circular variance (Batschelet, 1981). Direction selectivity was quantified using direction index (DI), a normalized difference between the responses for the preferred and direction of motion and its opposite, as follows:

$$
\mathrm{DI}=\frac{R\left(\theta_{\text {pref }}\right)-R\left(\theta_{\text {pref }+180^{\circ}}\right)}{R\left(\theta_{\text {pref }}\right)} .
$$

Contrast responses were fit using the Naka-Rushton equation (Naka and Rushton, 1966; Albrecht and Hamilton, 1982; Heimel et al., 2005), as follows:

$$
R(c)=R_{s}+\frac{g c^{n}}{c_{50}^{n}+c^{n}},
$$

where $R_{s}$ is the spontaneous firing rate; $c$ is contrast; and fitting parameters are contrast at half-peak response ( $c 50)$, gain $(g)$, and exponent $(n)$. Relative maximum gain (RMG) was calculated from the fits as the maximum slope of the contrast-response curve when the difference between maximum firing rate and spontaneous firing rate is normalized to 1 . RMG indicates the linearity of the contrast-response curve, with 1 being completely linear. The contrast saturation index (SI; Peirce, 2007) was defined as follows:

$$
S I=\frac{R_{\max }-R(100 \%)}{R_{\max }-R(0)}
$$

and indicates the degree of "supersaturation" of the contrast response (i.e., the amount the response might be reduced at $100 \%$ contrast compared with the contrast that produces the maximum response, which might or might not be at $100 \%$ ).

Size-tuning responses were fit to a product of two functions that represented the center response $\left(R_{\text {center }}\right)$ and the modulation of the center response, respectively, as follows:

$$
R(r)=R_{\text {center }}(r) R_{\bmod }(r) .
$$

The $R_{\text {center }}$ is the response of a Gaussian receptive field with the stimulus $S(x, y)$, as follows:

$$
R_{\text {center }}(r)=\sum_{x} \sum_{y} S(x, y) * A * G(x, y, \mu, \Sigma),
$$

where $A$ is the amplitude of the response (in spikes/s), $\mu$ is the center position of the stimulus on the screen, and $\sum$ is the covariance matrix. Here, we constrained the Gaussian function to be circular by defining $\sum=\left|\begin{array}{ll}c & 0 \\ 0 & c\end{array}\right|$.

The modulating function $\left[R_{\bmod (\mathbf{r})}\right]$ takes values between 0 and 2 and is proportional to the overlap of the stimulus and a circle of radius $R_{\max \_s t i m}$, as follows: 


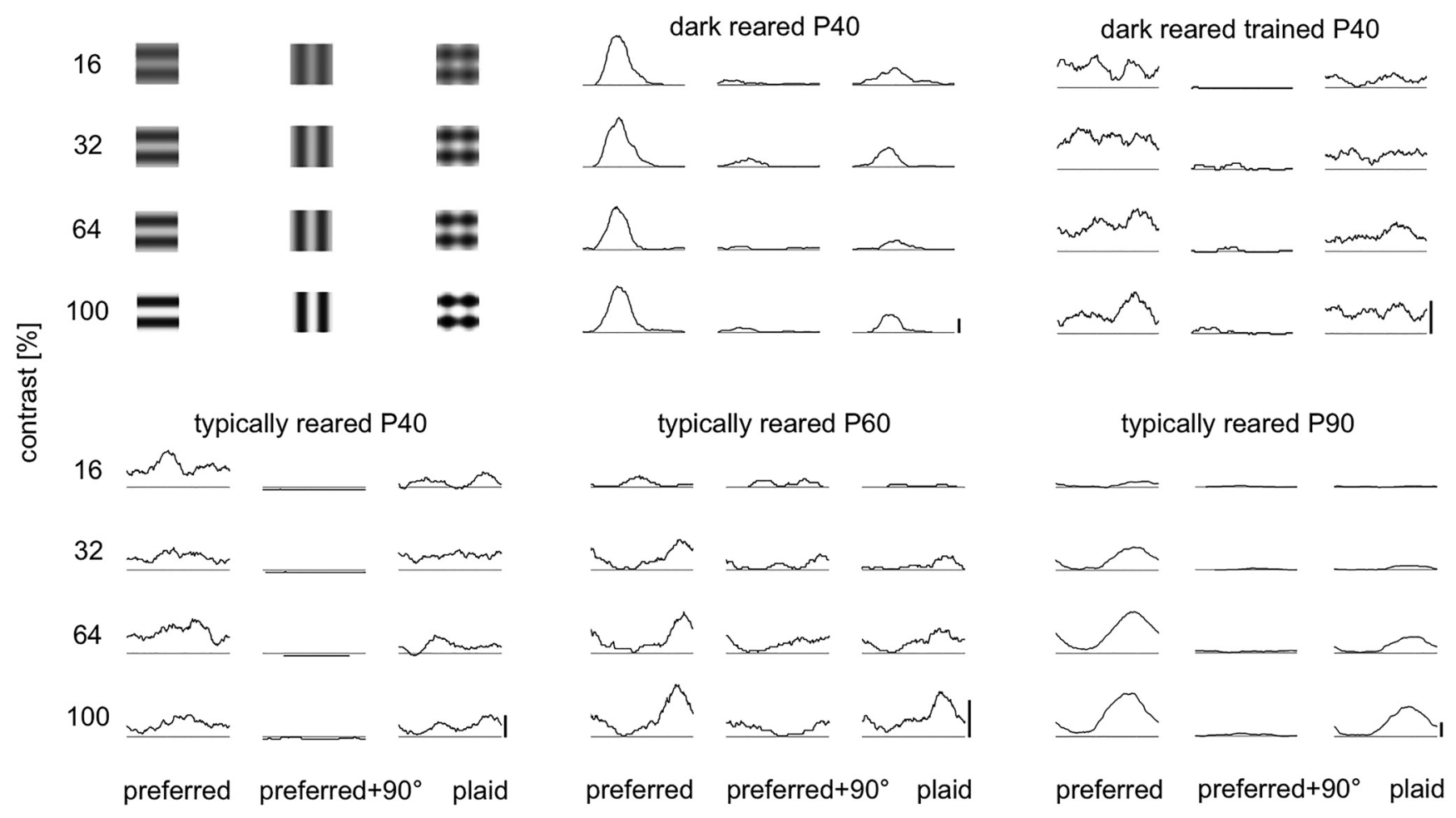

Figure 2. Representative cells in all experimental conditions exhibit cross-orientation suppression. For each cell, cycle-averaged responses to stimulation at the preferred direction, the orthogonal direction, and a plaid combination of the two stimuli are shown, for a variety of stimulus contrasts. Time is on the horizontal axis (showing one grating cycle). Vertical axis indicates response; bars denote 10 spikes/s.

$$
R_{\text {mod_circle }}(r)=1+S_{m} \frac{r^{2}}{R_{\text {max_stim }}^{2}} .
$$

When the stimulus was an aperture, the modulating response was as follows:

$$
R_{\text {mod_aperture }}(r)=1+S_{m} \frac{R_{\text {max_stim }}^{2}-r^{2}}{R_{\text {max_stim }}^{2}} .
$$

We quantified size tuning using two measurements, the size modulation parameter $\left(S_{m}\right)$ and the stimulus size when $R_{\text {center }}$ exhibited half of its maximum response. $S_{m}$ takes positive values for cells that exhibit length summation, and negative values for cells that exhibit surround suppression.

Cross-orientation suppression was characterized in all cells using circular plaid stimuli consisting of two superimposed drifting sinusoidal gratings. One of the component gratings was assigned the previously established preferred orientation of the cell, and the other component grating was assigned the orthogonal orientation. The direction of drift for the orthogonal grating was taken to be the preferred direction plus $90^{\circ}$. Response to the plaid stimulus can be related to the linear combination of responses to the component gratings, as follows:

$$
R_{\text {pref }+ \text { orth }}=P m\left(R_{\text {pref }}+R_{\text {orth }}\right) .
$$

The plaid multiplier $\left(P_{m}\right)$ is used to quantify the magnitude of the suppression of the response to the preferred orientation by the orthogonal orientation. Higher values of the plaid multiplier denote lower values of cross-orientation suppression.

\section{Computer code}

All computer code related to this study is available at http://github.com/ VH-Lab/vhlab_publishedstudies and depends on libraries available at http://code.vhlab.org.

\section{Results}

Our primary goal was to examine the influence of visual experience and age on the development of several receptive field properties. In particular, we were interested in uncovering whether cross-orientation suppression and size tuning depend on visual experience. To this end, we raised ferrets under three different conditions that were each designed to test a possible relationship between experience and selectivity. Typically reared animals received $12 \mathrm{~h}$ of visual experience daily, so they were exposed to complex natural scenes with objects of different sizes and mixtures of stimulus orientations. We recorded from animals living under typical rearing conditions at the following three different ages: P40, P60, and P90. Dark-reared animals were raised in $24 \mathrm{~h}$ constant darkness that was interrupted by two brief testing sessions (see Materials and Methods) and had very impoverished visual experience. A third group of animals was dark reared but provided with two daily $1.5 \mathrm{~h}$ "training" sessions for $5 \mathrm{~d}$, where the animals were exposed to stimulation with sinusoidal gratings of a single orientation that occupied the full screen. Experience could be important for the development of cross-orientation suppression or size tuning; furthermore, experience with multiple orientations or objects of varying size might be necessary. The third experimental group was designed to test just that, whether the quality of visual experience influences the emergence of crossorientation suppression and size tuning.

We examined the refinement of receptive field properties at times related to the anatomical maturation of the visual cortical circuit (White and Fitzpatrick, 2007). Long-range horizontal connections extending for millimeters across the cortical surface exhibit adult levels of complexity at approximately P35 to P45 (Durack and Katz, 1996; Ruthazer and Stryker, 1996; White et al., 


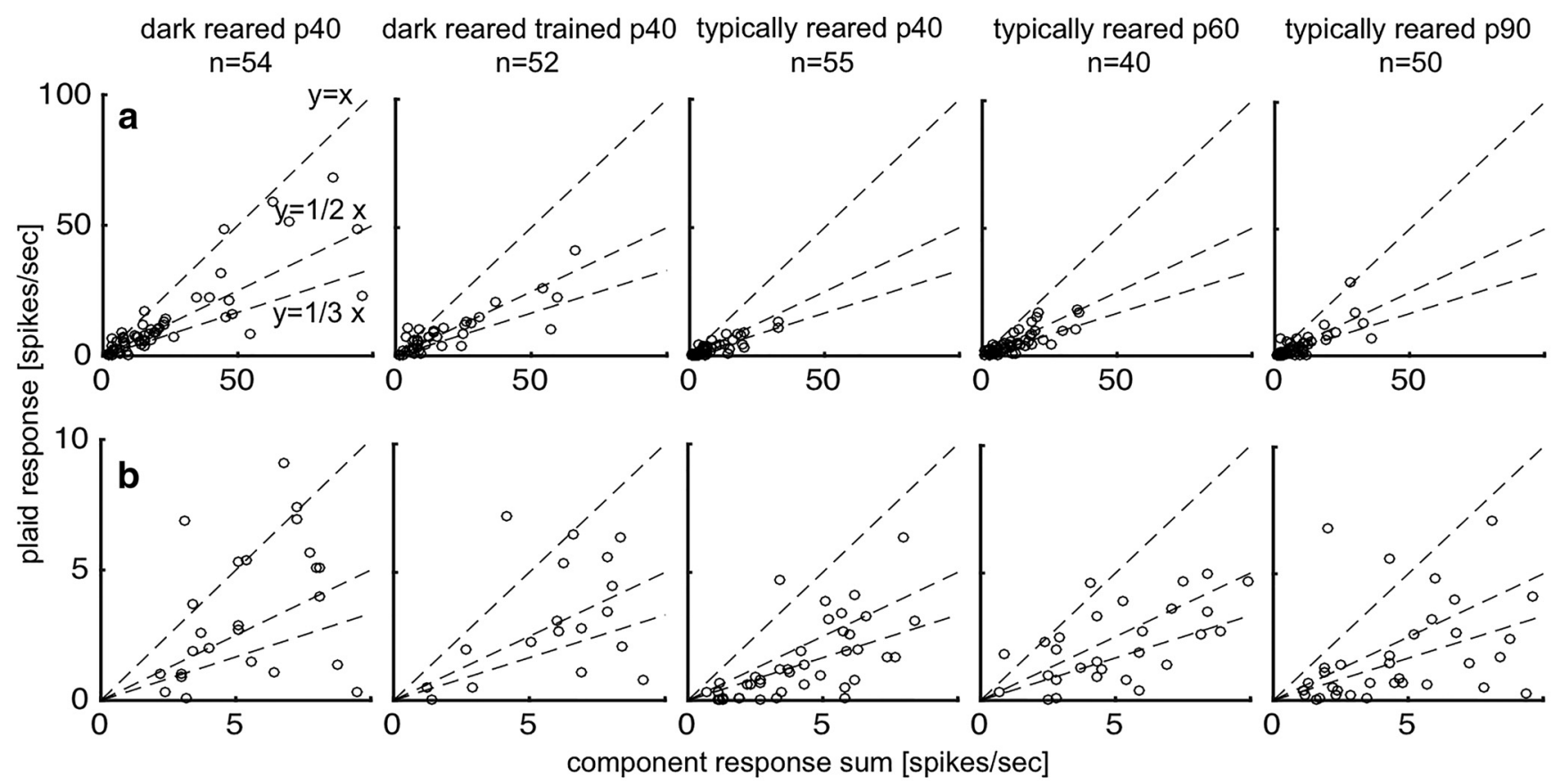

Figure 3. Cells in all animal groups exhibit robust cross-orientation suppression. Scatterplots of responses to plaid stimulation plotted against the linear sum of the response to preferred stimulation and orthogonal stimulation (i.e., the component response sum) for stimuli of $100 \%$ contrast. Dashed lines show slopes $y=x, y=1 / 2 x$, and $y=1 / 3 x$. $\boldsymbol{a}$ displays the full range of data, and $\boldsymbol{b}$ displays data in the $0-10$ spikes/s range.
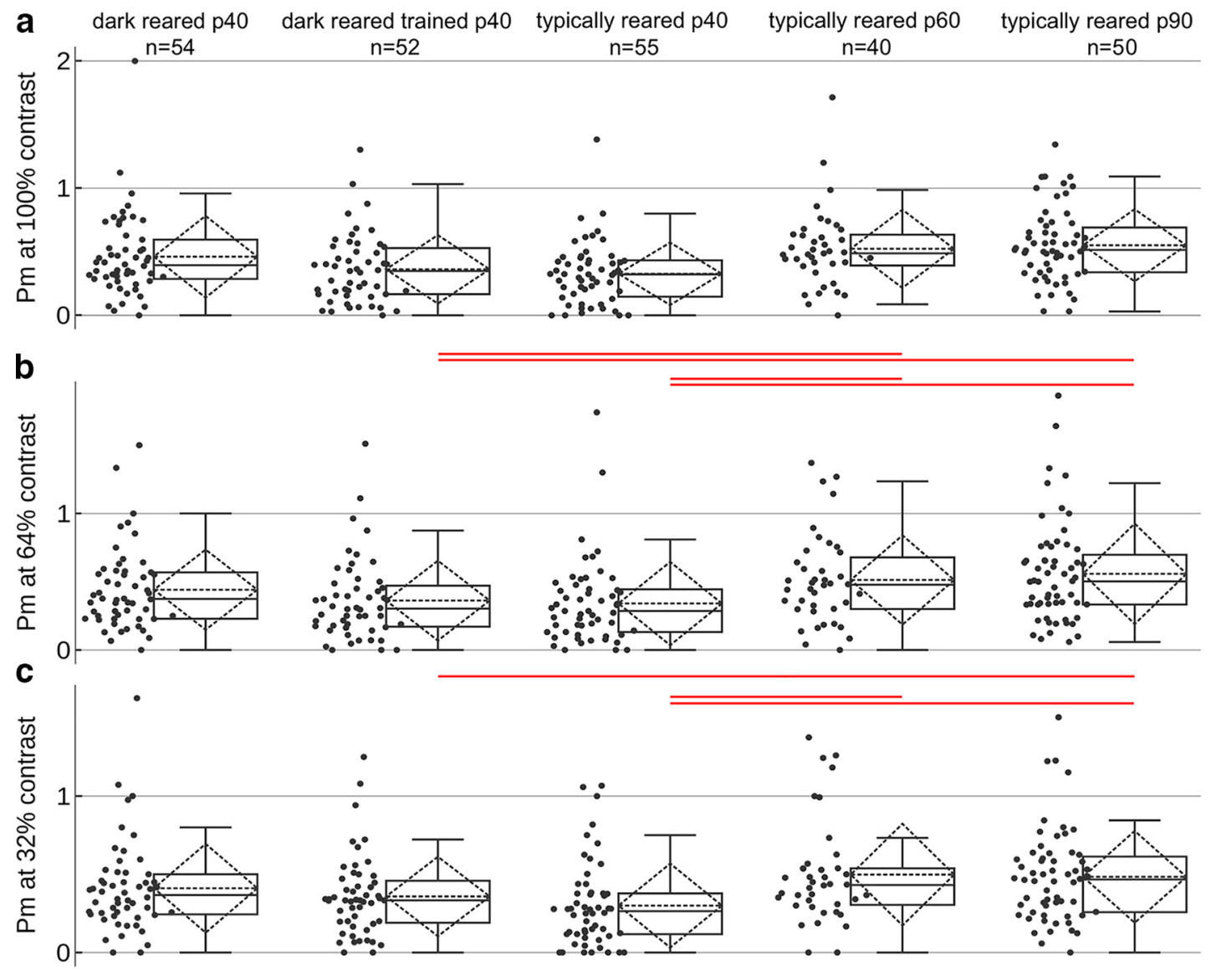

Figure 4. Median cross-orientation suppression varies slightly across age and condition. $P_{m}$ values are shown for all cells across all groups at a) $32 \%$, b) $64 \%$, and c) $100 \%$ contrast. For each group, all data points are shown at the left, and a box-and-whisker plot is shown at the right. The horizontal line in the center of each dotted diamond indicates the mean, and the dotted diamond tips are at \pm 1 SD. Lower $P_{m}$ values indicate higher suppression. There is a slight increase in suppression in typically reared P40 animals at all contrasts, and cross-orientation suppression reduces slightly at P60 and P90. Dashed lines are at 0.5 and 1. Red lines indicate pairwise differences significant at $p<0.05$ (Bonferroni-corrected Kruskal-Wallis test). 
2001); volumetric synaptic density achieves adult levels at approximately P90 (Erisir and Harris, 2003). In principle, either of these anatomical features could underlie the development of cross-orientation suppression or size tuning. This study allowed us to connect these landmark events in the development of the visual cortical circuit to the changes in response properties of V1 neurons. A diagram of all animal groups is shown in Figure 1.

After isolating a cell, we assessed its direction tuning, followed by its spatial frequency tuning and temporal frequency tuning. All subsequent measurements were made with gratings that were aligned to the optimal direction, spatial frequency, and temporal frequency properties of the cell of interest. Then, we examined contrast responses, cross-orientation suppression, and size tuning. To our knowledge, the experience and age dependence of cross-orientation suppression and size tuning have not been examined previously, so we turn our attention to these results first, followed by orientation selectivity, direction selectivity, spatial and temporal frequency tuning, contrast responses, and evoked firing rates.

\section{Cross-orientation suppression}

Cross-orientation suppression was robustly present in all animal groups in our study. We assessed cross-orientation suppression at several contrasts with a stimulus that was $10^{\circ}$ by $10^{\circ}$ in size. Figure 2 shows responses from typical cells from animals in each experimental group. Responses to plaid drifting gratings were nearly always smaller than the sum of the individual responses to the two component directions. One of the two component gratings always had the preferred orientation of the cell and drifted in the preferred direction, while the other component grating had the orthogonal orientation (Fig. 3).

Although cross-orientation suppression was present in all experimental groups, the amount of suppression that we observed varied slightly with age and experience. We quantified cross-orientation suppression with a $P_{m}$ that compared the actual response to a plaid stimulus to the linear sum of the two components (Fig. 4). A value of 1 would indicate perfect linear summation, and a value $<1$ indicates cross-orientation suppression. The Kruskal-Wallis $\mathrm{H}$ test shows a statistically significant effect of experimental condition on the plaid multiplier for all three contrast levels tested $\left(32 \%, \chi^{2}(4)=22.15, p=0.000 ; 64 \%, \chi^{2}(4)=\right.$ $22.23, p=0.000 ; 100 \%, \chi^{2}(4)=29.09, p=0.000$ ). Interestingly, cross-orientation suppression in typically reared animals showed an increase with experience at P40 (compared with dark-reared animals), but this initial increase in suppression was followed by a subsequent decrease at P60 and P90. Gaussian center region.
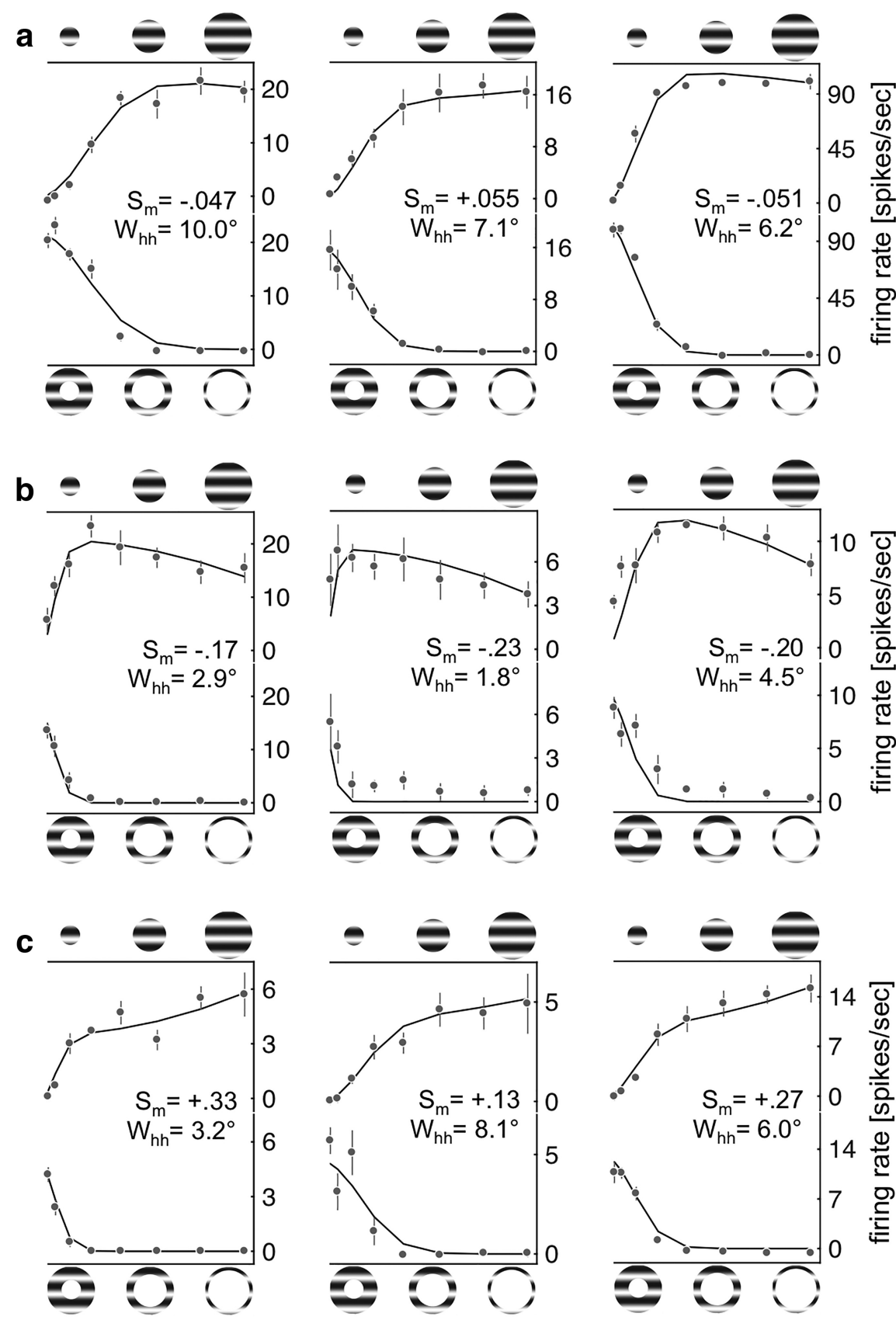

Figure 5. Diversity of size-tuning curves in ferret visual cortex. Cells were fit to a Gaussian center and a circular modulating region (see Materials and Methods). $\boldsymbol{a}-\boldsymbol{c}$, Size-tuning curves and corresponding fits for three broad groups of response categories: cells that exhibit a plateau but are not modulated by stimulation in the surround $\left(S_{m} \sim 0 ; \boldsymbol{a}\right)$; cells that exhibit surround suppression $\left(S_{m}\right.$ negative; $\left.\boldsymbol{b}\right)$; and cells that exhibit length summation $\left(S_{m}\right.$ positive; $\left.\boldsymbol{c}\right)$. The top panel for each cell shows responses to stimuli of increasing size $\left(3^{\circ}, 6^{\circ}, 11^{\circ}, 19^{\circ}, 29^{\circ}, 39^{\circ}, 48^{\circ}, 54^{\circ}\right)$, while the bottom panel shows responses to an annulus of increasing inner diameter (same sizes). Responses to both classes of stimuli were used to construct the fits. $\mathrm{W}_{\mathrm{hh}}$, Full-width at half-height of the

\section{Size tuning}

We next examined the developmental profile of size tuning. Studies (Gilbert, 1977; Chisum et al., 2003) have shown that cells can exhibit a wide variety of responses to large stimuli. Some cells merely plateau in response to increasing stimulus size (Fig. 5a). Other cells exhibit surround suppression, where stimulation outside of the classical receptive field induces weaker responses to central stimulation (Fig. 5b). Finally, still other cells show length summation, where the responses of cells to stimuli that exceed the classical receptive field keep 

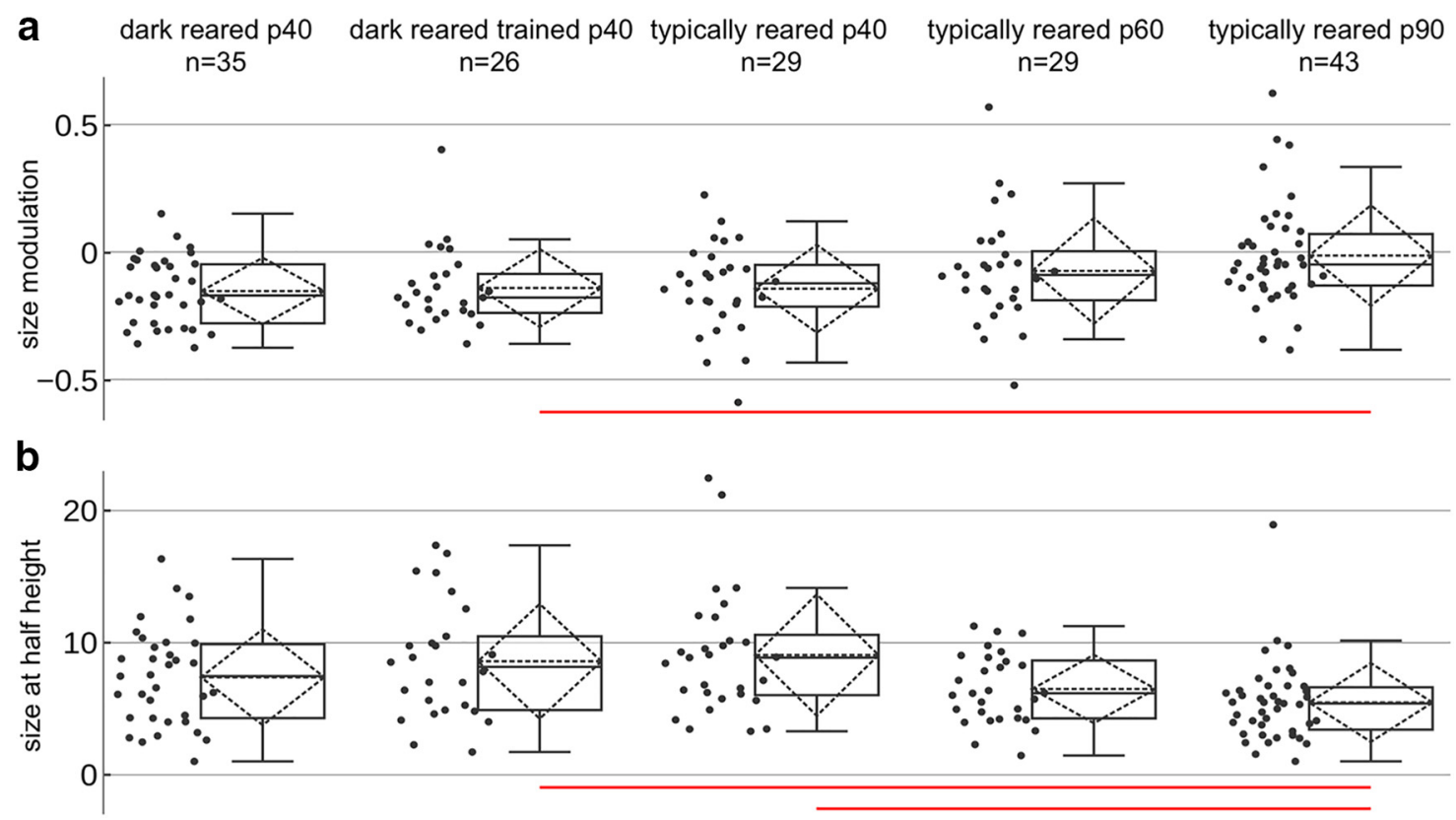

Figure 6. Size-tuning properties across age and experience. $\boldsymbol{a}$, Parameter $S_{m}$; cells that exhibit plateau responses and surround suppression are found in all animals, but cells that exhibited substantial length summation were found more commonly in the oldest animals. Red lines indicate pairwise differences (Kruskal-Wallis test, Bonferroni corrected, $p<0.05$ ). $\boldsymbol{b}$, As expected from earlier reports, receptive field size as assessed by the full-width at half-height $\left(\mathrm{W}_{\mathrm{hh}}\right)$ of the Gaussian center component exhibited decreases with experience and was smallest in the oldest animals examined. Red lines indicate pairwise differences (paired $t$ test with Bonferroni correction) significant at $p<0.05$. Note that the major reduction of receptive field size occurs after other properties like orientation and direction selectivity have been established.

increasing (Fig. 5c). We observed all of these response types in our animals.

To evaluate these responses quantitatively, we developed a fit function that included a Gaussian center component that was modulated by a circular surround component (see Materials and Methods). The degree of surround modulation was quantified by a single parameter, $S_{m}$, that was negative when stimulation of the surround was suppressive and was positive when the stimulation of the surround was enhancing. This parameter took values near 0 when surround stimulation did not influence the firing of the neuron. We examined responses to stimuli of increasing size and annular stimuli of decreasing inner diameter, and both sets of responses were used to establish the fits. Analysis of the responses to the annular stimulus allowed us to delineate the classical receptive field center (where stimulation evokes a response) from the surround that merely modulates responses to the center stimulus.

We observed plateau responses and surround suppression in all animal groups (Fig. $6 a$ ), indicating that these variants of size tuning do not require visual experience for their expression. The fraction of neurons that exhibited substantial length summation increased in the oldest animals in the study (Fig. 6a). Because we did not modulate visual experience in the oldest animals in our study, we cannot conclude whether these results are due to age or experience, but these responses do emerge at a time when the horizontal connections across the cortical surface have already reached anatomical maturity (Durack and Katz, 1996; Ruthazer and Stryker, 1996; White et al., 2001).

Consistent with prior reports, we observed a substantial decrease of receptive field center size in the oldest animals (Fig. 6b). Median receptive field center sizes dropped from $7.5^{\circ}$ in dark-reared animals to $5.4^{\circ}$ in the $\mathrm{P} 90$ animals. This maturation coincides with the peak synapse density in layer 2/3 in ferrets (approximately P90; Erisir and Harris, 2003; White and Fitzpatrick, 2007).

\section{Orientation and direction selectivity}

Previous studies (Chapman and Stryker, 1993; White et al., 2001; Li et al., 2006b) have found that orientation selectivity is present at the time of eye opening and that it increases with the onset of visual experience. Direction selectivity, on the other hand, is almost entirely absent at the time of eye opening, emerges over several days, and requires visual experience ( $\mathrm{Li}$ et al., 2006b). Our results largely recapitulated these prior observations: dark-reared animals exhibited moderately strong orientation selectivity that increased with visual experience; and dark-reared animals exhibited very weak direction selectivity that was also increased by visual experience (Fig. 7).

These data also give us a new view of the impact of visual experience with simple grating stimuli on orientation and direction selectivity. Previous work has demonstrated that only a few hours (3-9 h) of experience with a moving visual stimulus is sufficient to cause the rapid emergence of direction selectivity and a concurrent increase in orientation selectivity ( $\mathrm{Li}$ et al., 2008; Van Hooser et al., 2012; Ritter et al., 2017). However, for methodological reasons, these experiments only assessed orientation and direction selectivity immediately after exposure to the "training stimulus," leaving open the possibility that the effects of such visual experience were transient. In this study, recordings were obtained $1-5 \mathrm{~d}$ after the last training session, allowing us to address this possibility. Dark-reared and trained animals exhibited direction selectivity that was intermediate between darkreared animals that did not have training and animals with typical visual experience. P40 dark-reared animals exhibited direction selectivity that was significantly lower than P40 typically reared animals. A direct comparison between dark-reared animals and trained dark-reared animals did not reach significance $(p=0.09$, Kruskal-Wallis test), but trained and dark-reared animals exhibited direction selectivity that was not different from that of typi- 
a

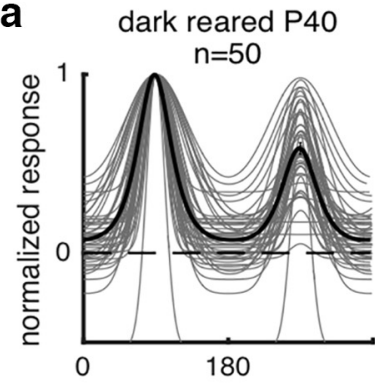

b

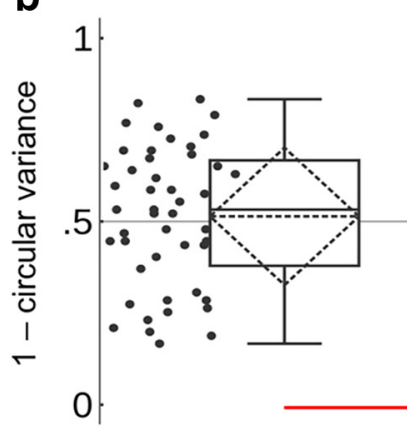

dark reared trained $\mathrm{P} 40$

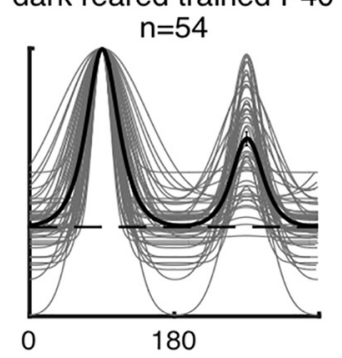

typically reared $\mathrm{P} 40$

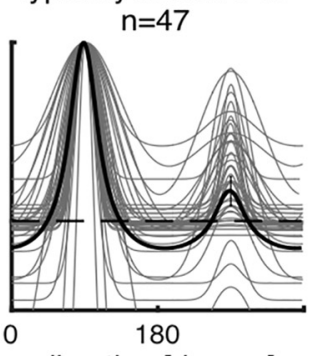

direction [degree]
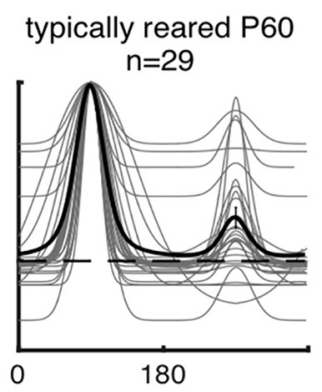

$0 \quad 180$

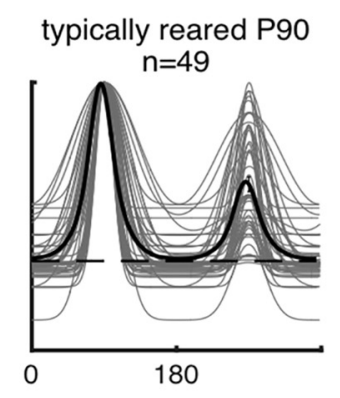

d P90

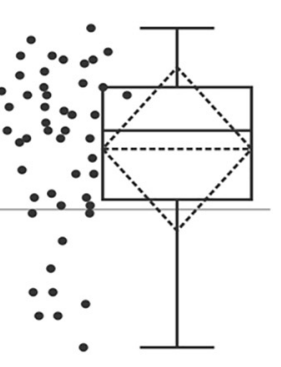

c

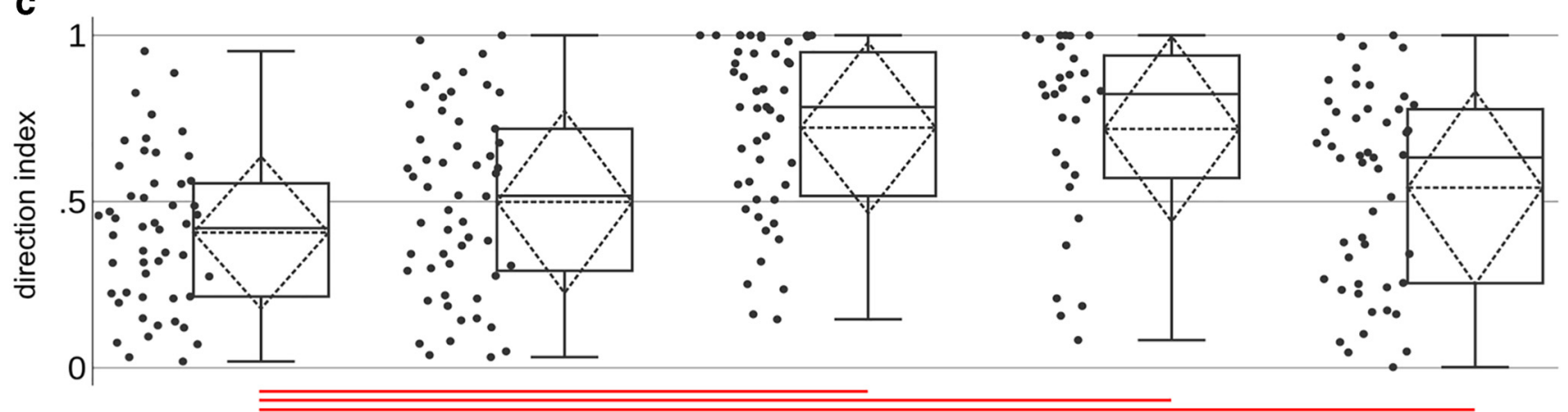

Figure 7. Effects of experimental condition on the development of orientation and direction tuning. $\boldsymbol{a}-\boldsymbol{c}$, Normalized direction-tuning curves for the five experimental conditions $(\boldsymbol{a})$; orientation selectivity quantified as 1 - circular variance $(\boldsymbol{b})$; and direction selectivity quantified as the direction index (c). Dashed lines are at $0.5 \mathrm{Dl}$ and 1 - circular variance; red lines indicate pairwise differences significant at $p<0.05$ (Kruskal-Wallis test, Bonferroni correction). As expected from previous studies, both orientation selectivity and direction selectivity exhibit increases with experience. Unexpectedly, direction selectivity reached a peak at P40/P60 and reduced slightly at P90, consistent with the idea that direction selectivity does not develop in a monotonic manner.

cally reared P90 animals (Fig. 7c; $p<0.0033$, Kruskal-Wallis test with Bonferroni correction), which show some substantial direction selectivity. This evidence suggests that the exposure to the training stimulus did produce relatively lasting, if small, changes in receptive field properties.

Finally, we were surprised to observe that direction selectivity changes nonmonotonically with age. We observed the strongest direction selectivity in P40 animals that were typically reared. Direction selectivity index values decreased at P90, but still remained well above the values of visually naive animals. This result suggests that selectivity for some features goes through periods of increases and decreases as the animal matures.

\section{Spatial and temporal frequency tuning}

The spatial frequency preference showed a substantial and expected dependency on experience. Spatial frequency was characterized in all cells using drifting sinusoidal grating stimuli of varying spatial frequencies $(0.05,0.1,0.15,0.2,0.3,0.5$, and 0.8 cycles $/{ }^{\circ}$ visual angle), $4 \mathrm{~Hz}$ temporal frequency, $100 \%$ contrast, and orientation and direction fixed at the previously established optimal value for each cell. As expected from previous reports, cells from animals in the P40 age group prefer lower spatial frequencies regardless of rearing condition (Fig. $8 a, b$ ), consistent with the lower resolution of vision in younger animals, which likely includes developmental effects of the optical quality of the eye, retina, and LGN (Freeman and Marg, 1975; DeAngelis et al., 1993; Tavazoie and Reid, 2000; Akerman et al., 2002; Heimel et al., 2007). In the two older groups, P60 and P90, the spatial frequency preference shifted toward higher frequencies. There was also a noticeable diversification of SF preferences with age-SF preferences of individual cells in younger animals were more tightly clustered. Conversely, in older animals, cells preferred higher SFs, and their preferences had a larger spread.

The contribution of the development of the optical quality of the eye to these spatial frequency measures is probably not large. We know of no direct studies of the development of the ferret eye, but we can make inferences from electrophysiological studies. Previous studies (White et al., 2001) have found that typically reared animals exhibit a slight horizontal bias in orientation preference, whereas dark-reared animals exhibit a slight vertical bias. These results indicate that the lens of the ferret is capable of transmitting both orientations at this developmental age. Fur- 

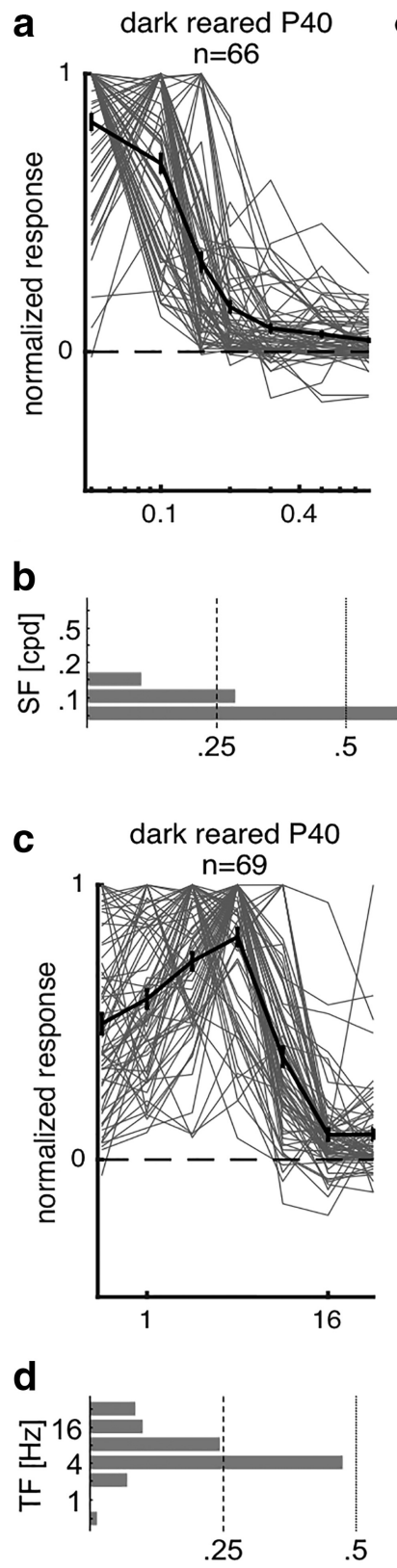

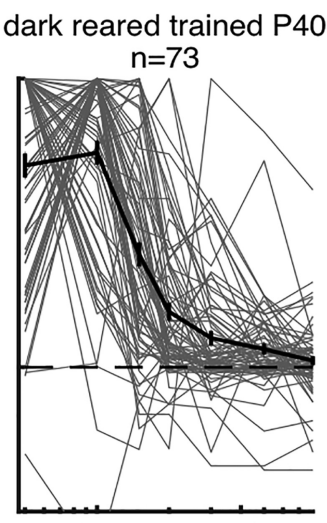

0.1 typically reared $\mathrm{P} 40$

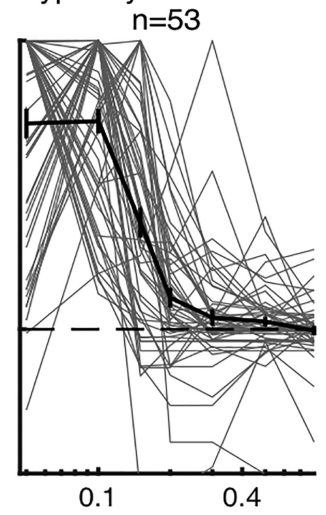

spatial frequency [cycles/degree]
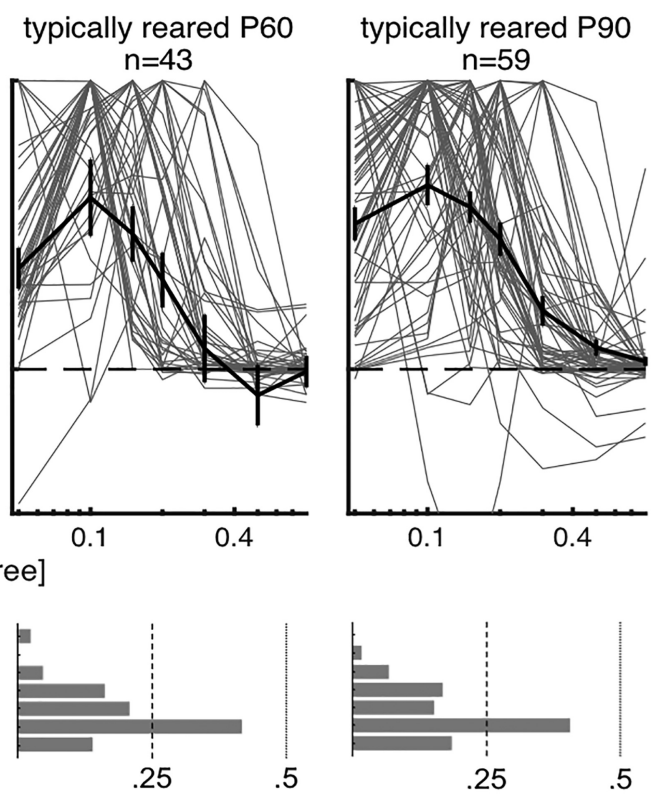
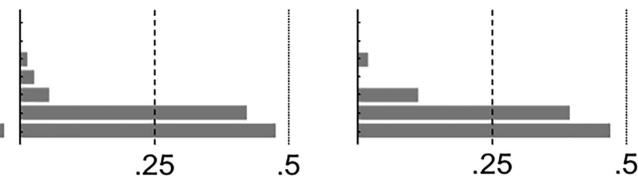

dark reared trained $\mathrm{P} 40$
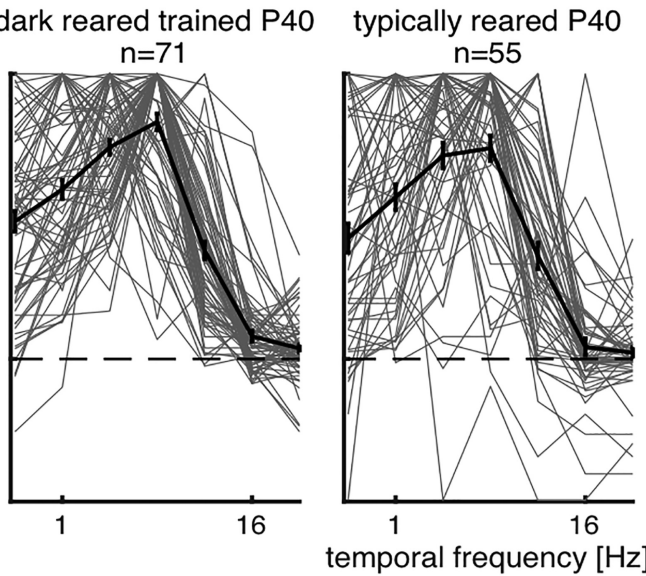

typically reared P60

typically reared P90
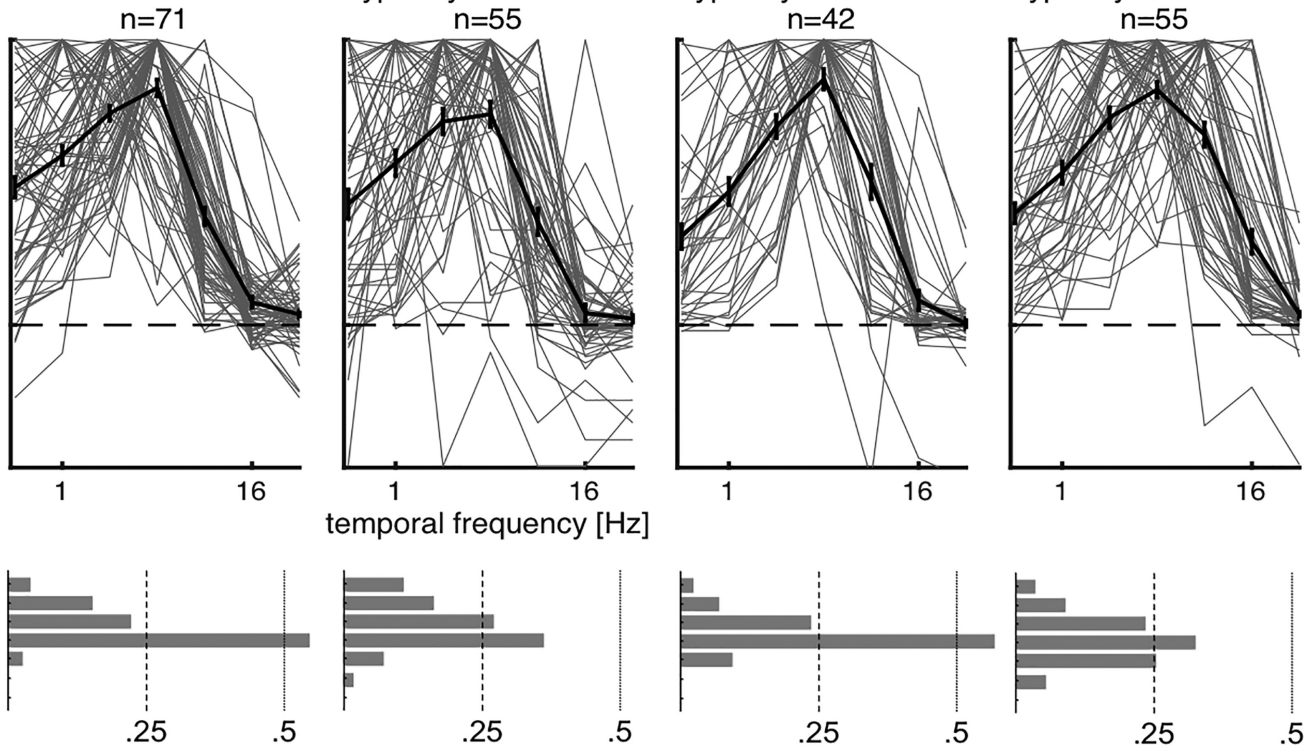

Figure 8. Effects of experimental condition on the development of spatial and temporal frequency preference. $\boldsymbol{a}, \boldsymbol{b}$, Normalized spatial frequency-tuning curves for the five experimental conditions $(\boldsymbol{a})$; normalized spatial frequency histogram $(\boldsymbol{b})$; ticks on the $y$-axis denote $0.05,0.1,0.15,0.2,0.3,0.5$, and 0.8 cycles $/{ }^{\circ}$ (cpd; bottom to top). $\boldsymbol{c}, \boldsymbol{d}$, Normalized temporal frequency-tuning curves for the five experimental conditions (c); normalized temporal frequency histogram (d); ticks on the $y$-axis denote $0.5,1,2,4,8,16$, and $32 \mathrm{~Hz}$ (bottom to top). As expected from previous studies, and consistent with decreases in receptive field size that are reported in Figure 6, spatial frequency preferences exhibited slight increases with age, indicating that the spatial resolution of visual processing increases with age. Temporal frequency preferences were relatively constant over the ages and rearing conditions studied here.

ther, ferrets have smaller eyes than cats, and smaller eyes have a larger depth-of-field (Green et al., 1980), suggesting that images should be in focus over a wider range.

Temporal frequency preferences were subject to fewer differences across the experimental groups compared with selectivity to other features. Temporal frequency was characterized in all cells using drifting sinusoidal grating stimuli of varying temporal frequency $(0.5,1,2,4,8,16$, and $32 \mathrm{~Hz}) ; 100 \%$ contrast; and spatial frequency, orientation, and direction fixed at the previously established optimal value for each cell. Cells from animals in the P40 and P60 age groups preferred lower TFs regardless of rearing condition (Fig. $8 c, d$ ). In the $\mathrm{P} 90$ age group, TF preference shifted slightly toward higher frequencies, but these changes were quite modest.

\section{Contrast tuning}

Contrast tuning was subject to subtle differences across the different animal groups. Contrast responses were examined in all cells using drifting sinusoidal grating stimuli of varying contrast $(2 \%, 4 \%, 8 \%, 16 \%, 32 \%, 64 \%$, and $100 \%)$, and with temporal frequency, spatial frequency, and direction fixed at the previously established optimal values for each cell (Fig. 9). There were no statistically significant differences among RMG values for different conditions (Fig. 9b). There were small but significant differences in the amount of "supersaturation" that was exhibited by neurons in these different groups. The median value for all groups was very close to 0 (no supersaturation), but a few cells were substantially suppressed at the highest contrast (Fig. 9c). Overall, visual experience and age appeared to have only a modest impact 
a

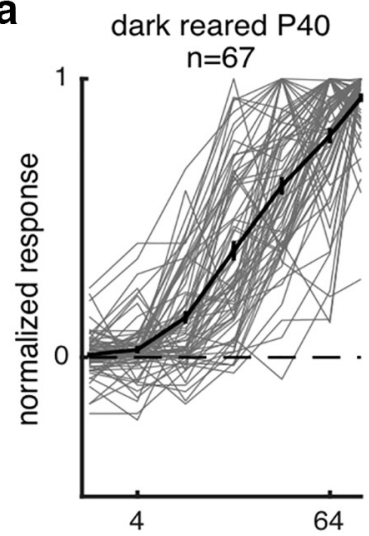

b

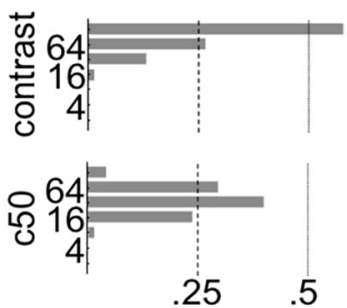

dark reared trained $\mathrm{P} 40$
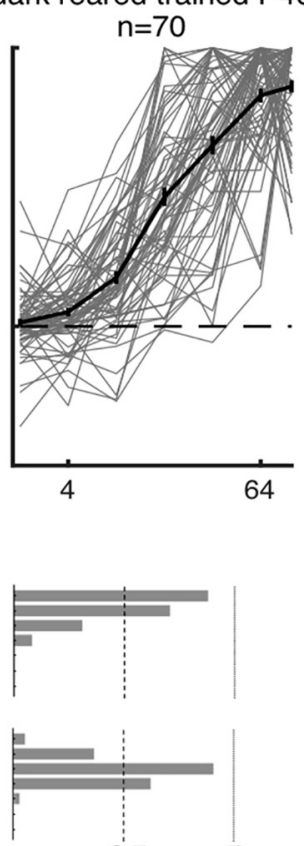

.25 typically reared $\mathrm{P} 40$
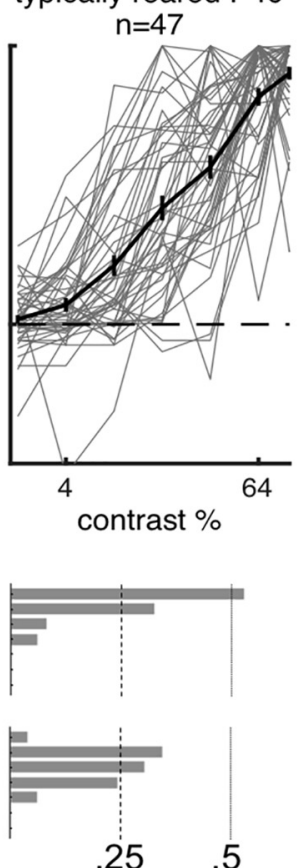

typically reared $\mathrm{P} 60$

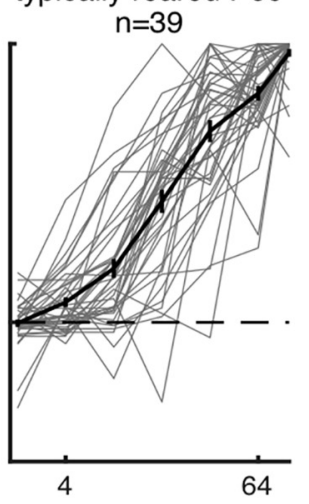

typically reared P90

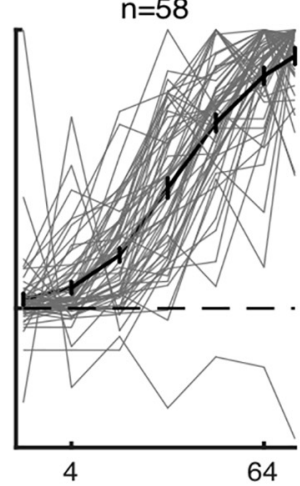

\section{C}
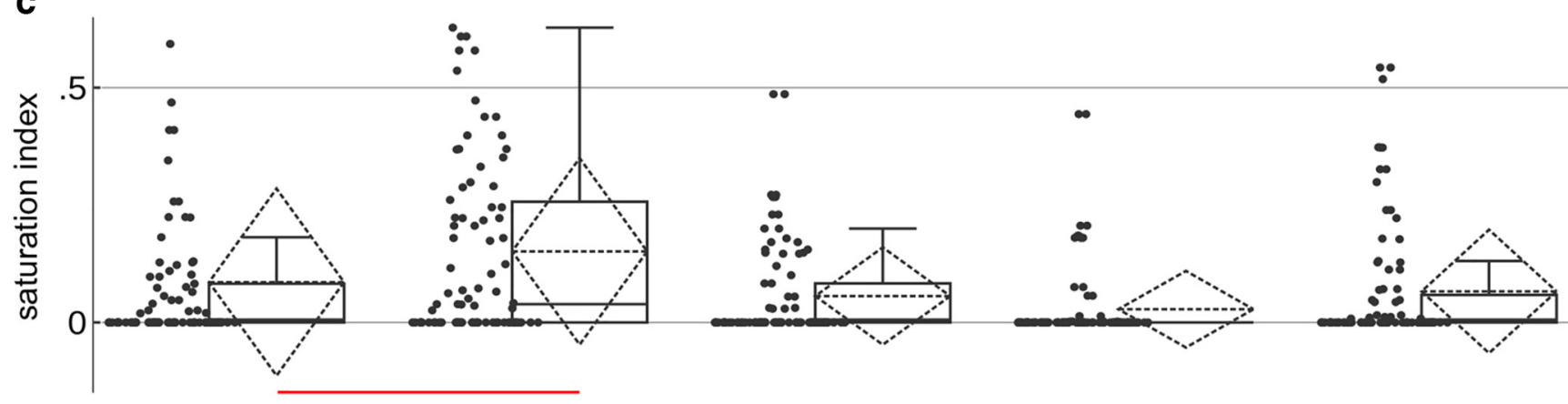

d

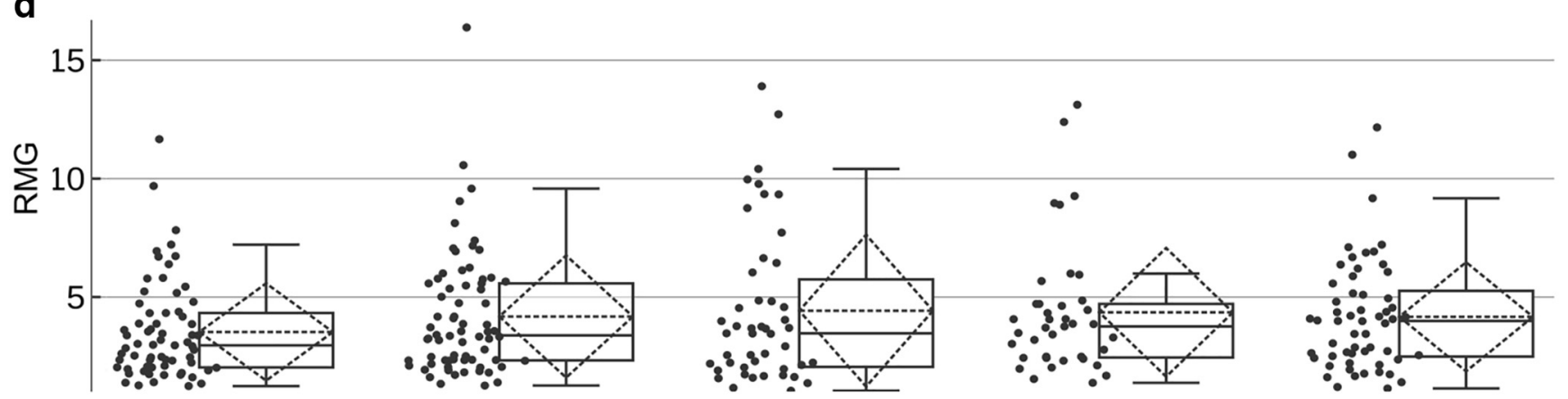

Figure 9. Effects of experimental condition on the development of contrast preference. $\boldsymbol{a}-\boldsymbol{d}$, Normalized contrast-tuning curves for the five experimental conditions ( $\boldsymbol{a}$ ); contrast at peak (top) and half-peak response (bottom; $\boldsymbol{b}$ ); saturation index of the contrast-response curve (c); and linearity in response to contrast quantified by relative maximum gain, with lower values indicating more linearity $(\boldsymbol{d})$. Red lines indicate pairwise differences significant at $p<0.05$. Contrast responses were relatively constant over the developmental ages and rearing conditions studied here, with some slight variation in saturation index.

on contrast responses. In principle, a large impact on contrast responses could have had major implications for cross-orientation suppression, but neither property exhibited substantial changes across development.

\section{Firing rate}

One major parameter that exhibited a large change with age was evoked firing rate. The maximum evoked firing rate was taken to be the strongest trial-averaged response to sinusoidal grating stimulation that we observed (i.e., the response measured at the preferred direction, spatial frequency, temporal frequency, and best contrast). Evoked maximum firing rates began at $\sim 10 \mathrm{~Hz}$ in young animals, but increased substantially in the $\mathrm{P} 90$ animals to $\sim 20 \mathrm{~Hz}$ on average (Fig. 10). The Kruskal-Wallis $\mathrm{H}$ test shows a statistically significant effect of experimental condition on firing rate $\left(\chi^{2}(4)=23.00, p=0.000\right)$. We observed no difference in the 


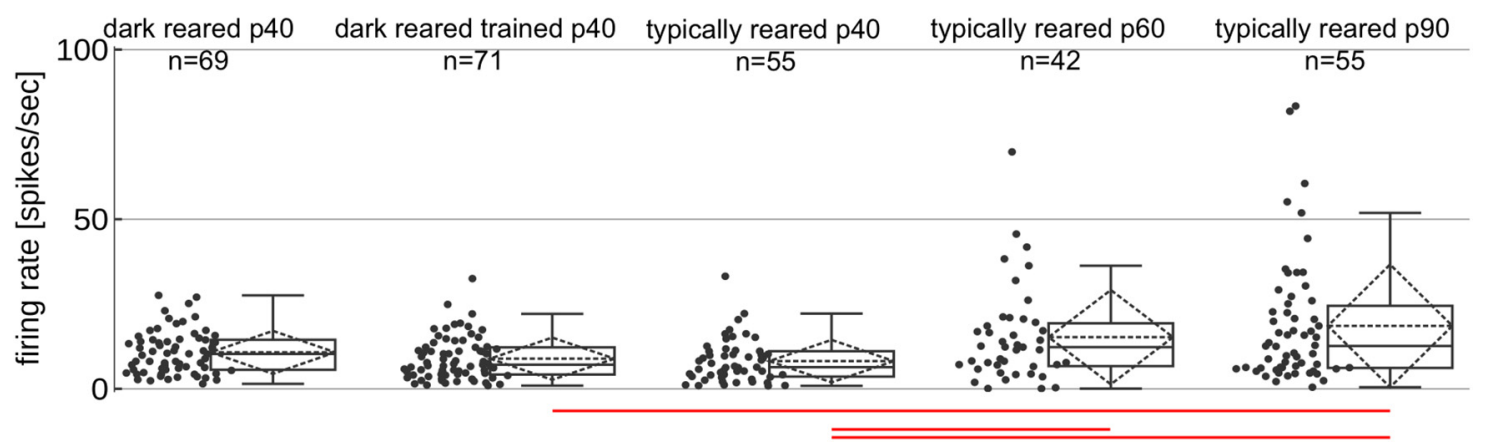

Figure 10. Firing rate across experimental conditions. Red lines indicate pairwise differences (Kruskal-Wallis test, Bonferroni corrected) significant at $p<0.05$. The oldest animals exhibited substantially higher firing rates than younger animals.

median evoked firing rate across the three rearing conditions at $\mathrm{P} 40$, but large firing rates $(>40 \mathrm{~Hz})$ were observed only in the two older groups. These findings suggest that the network changes that support high firing rates are still emerging, even after 1 month of visual experience (P60).

\section{Discussion}

We characterized the role of visual experience and age on the development of $\mathrm{V} 1$ receptive field properties in the ferret. We found that cross-orientation suppression and surround suppression were present regardless of whether the animal had any experience with visual stimuli. In addition, we found that increases in direction selectivity produced by short-term exposures to moving visual stimuli were retained over days. Direction selectivity peaked at P40 and decreased slightly afterward. Finally, we observed that length summation and high evoked firing rates were found in the oldest animals (P90).

\section{Experimental design}

All P40 animals were exposed to two 80-min-long blocks of visual experience each to obtain data for an unrelated study (see Materials and Methods). This was done to maximize the yield of research animals. In previous studies, we have not observed substantial influence of visual experience on direction selectivity with $<3$ h of experience (Clemens et al., 2012; Roy et al., 2016; Ritter et al., 2017), so we think it is unlikely that this visual exposure had a substantial impact on the results here.

\section{Experience and normalization}

Normalization is a canonical computation of neural circuits (Carandini and Heeger, 2011; Angelucci et al., 2017). Crossorientation suppression has been observed in many areas, including V1 (Gizzi et al., 1990; Ringach et al., 2002), V2 (Rowekamp and Sharpee, 2017), V4 (Reynolds et al., 1999), middle temporal cortex (Britten and Heuer, 1999; Heuer and Britten, 2002), and inferior temporal cortex (Zoccolan et al., 2005). It is ubiquitous across species (Carandini and Heeger, 2011), being found in macaque (Ringach et al., 2002), cat (DeAngelis et al., 1992), mouse (Sato et al., 2016), and even Drosophila (Olsen et al., 2010). Surround suppression is also ubiquitous across species, being found in mouse (Van den Bergh et al., 2010; Self et al., 2014), ferret (Rubin et al., 2015), cat (Hubel and Wiesel, 1965; Blakemore and Tobin, 1972; Gilbert, 1977; DeAngelis et al., 1994; Sengpiel et al., 1997), monkey (Hubel and Wiesel, 1968; Sceniak et al., 1999; Jones et al., 2001; Cavanaugh et al., 2002a,b), and human (Williams et al., 2003; Zenger-Landolt and Heeger, 2003).

Due to the importance of normalization to selectivity in the presence of multiple stimuli (Barlow, 1961, 1972; Bauman and
Bonds, 1991; Somers et al., 1995; Carandini and Ringach, 1997; Lauritzen et al., 2001; Vinje and Gallant, 2002; David et al., 2004; Nurminen and Angelucci, 2014; Angelucci et al., 2017), it seemed possible that sensory experience with multiple stimuli might be necessary for its development. Our results provide strong evidence that sensory experience is unnecessary. Like orientation selectivity, normalization is robustly present at the onset of visual experience and in dark-reared animals, and was not greatly impacted by varying levels of experience.

Our results on size tuning are consistent with those obtained in behavioral (Li et al., 2013) and electrophysiological (Zhang et al., 2005) studies of young macaque monkeys. Surround suppression was present in the youngest monkeys studied. Behavioral length facilitation developed slowly over the first year of life. Our results extend these observations to include animals that were dark reared and provide further evidence that surround suppression is built in and that length summation occurs later.

\section{Circuits and normalization}

The circuit mechanisms of cross-orientation suppression and size tuning are still unclear. A portion of cross-orientation suppression is feedforward in nature: the suppression of cortical responses by adaptation does not remove cross-orientation suppression ( $\mathrm{Li}$ et al., 2006a), suggesting that LGN contributions must already exhibit some cross-orientation suppression (Li et al., 2006a; Priebe and Ferster, 2006). Other models posit that local connections within the cortex provide additional suppression, either via increased inhibition or reduced excitation (Somers et al., 1995; Haider et al., 2010; Sato et al., 2014; Rubin et al., 2015). These models are supported by evidence that the amount of suppression differs depending upon the position of a neuron within the maps of visual space and orientation (Das and Gilbert, 1999; Hashemi-Nezhad and Lyon, 2012; Koch et al., 2016). Still other models suggest that inhibition arises via feedback connections from higher cortical areas (Angelucci et al., 2002, 2017). Our results do not allow us to choose among these alternatives, but we can make one inference. Dark-reared animals showed strong cross-orientation suppression and typical rates of surround suppression, and prior research has noted that the long-range horizontal connections across the cortical surface are poorly formed in dark-reared animals (White et al., 2001). Therefore, it is unlikely that the long-range horizontal connections are a critical component for cross-orientation or surround suppression.

We observed the highest percentage of length-summing cells and the highest evoked firing rates in animals that had attained 2 months of visual experience (P90). The long-range horizontal connections are anatomically established by P35 to P45 (Durack and Katz, 1996; Ruthazer and Stryker, 1996; White et al., 2001), 
but excitatory synaptic density in layer $2 / 3$ does not peak until P80 to P100 (Erisir and Harris, 2003). Further, extrastriate feedback connections to $\mathrm{V} 1$ are present at eye opening and are pruned from eye opening to P70 (Khalil and Levitt, 2014). The refinement of these circuit elements could contribute to the emergence of these properties.

\section{Experience and direction selectivity}

The development of direction selectivity requires visual experience (Li et al., 2006b). Previous experiments have found that just 3-9 h of experience with moving stimuli causes the emergence of direction selectivity in visually naive ferrets (Li et al., 2008; Van Hooser et al., 2012; Roy et al., 2016; Ritter et al., 2017). Previous experiments were performed in acute preparations, and it was unknown whether these effects would persist for more than a few hours. We exposed dark-reared animals to $14-16 \mathrm{~h}$ of stimulation with large drifting grating stimuli. Stimulus delivery differed from previous studies in which the anesthetized ferrets were paralyzed to eliminate eye movements. Here, awake animals were head fixed but were free to move their eyes.

We found that the P40 animals that were dark reared and exposed to large moving gratings exhibited direction selectivity intermediate between those of P40 dark-reared animals and P40 typically reared animals. While the differences in direction selectivity between P40 dark-reared and dark-reared trained animals did not reach significance, $\mathrm{P} 40$ dark-reared and trained animals exhibited direction selectivity that was not different from P90 animals, which is evidence of modestly increased selectivity. This is evidence of the persistence of the influence of visual experience on direction selectivity.

We also found a surprising decline of direction selectivity in the second month of visual experience. Direction selectivity peaked at P40 and declined slightly afterward. This suggests that changes to direction selectivity over time are nonmonotonic, with direction selectivity increasing and decreasing as visual circuitry reaches maturity.

\section{Experience and development of receptive field properties}

One could imagine two broad ideas about how receptive field properties might be formed in primary sensory areas. Visual circuits could analyze the input statistics and design appropriate filters to encode this information. Indeed, when artificial cortical networks with learning rules are presented with natural scenes, the early filters in these networks resemble those of visual cortical neurons (Olshausen and Field, 1996; Bell and Sejnowski, 1997; van Hateren and van der Schaaf, 1998; Ranzato et al., 2007). Thus, in principle, it is possible that these response properties could be derived purely from experience.

But an alternative hypothesis-one that posits that efficient receptive field properties have been genetically derived through evolution - seems to be more consistent with experimental data. Orientation tuning, spatial and temporal frequency tuning, and normalization are present at the onset of the visual experience, and are only modestly altered by normal experience (Chapman and Stryker, 1993; DeAngelis et al., 1993; White et al., 2001; Li et al., 2006b; this article; but for abnormal experience creates highly aberrant receptive fields, see Mitchell, 1988; White et al., 2001; Prusky and Douglas, 2003). Experience is necessary for the development of cortical direction selectivity (Li et al., 2006b), but the tuning parameters that will emerge (angle preference and speed tuning) are already determined, and experience seems only to enhance the selectivity (Li et al., 2008; Roy et al., 2016; Ritter et al., 2017). The major contribution of experience, at least in V1, ap- pears to be the alignment of the inputs of the two eyes (Wang et al., 2010), some refinement of spatial frequency preferences (Mitchell, 1988), and the establishment of appropriate gains for selectivity (Turrigiano and Nelson, 2000).

These results provide one of two possible conclusions. It could be the case that the major properties of $\mathrm{V} 1$ neurons (except ocular alignment) are simply established by experience-independent mechanisms, such as molecular cues and modifications due to spontaneous activity (Meister et al., 1991; Ruthazer and Stryker, 1996; Cang et al., 2008). Or, perhaps, there are important experience-dependent modifications, but these modifications are not observable with the stimuli we have used here and would be apparent only when animals are viewing more natural stimuli (Berkes et al., 2011; Pecka et al., 2014).

Experience is clearly important to the mammalian brain, but whether its influence is instructive may depend on brain area or type of neural computation. The evidence presented here shows that cross-orientation suppression and surround suppression are present in ferrets independent of visual experience.

\section{References}

Adelson EH, Movshon JA (1982) Phenomenal coherence of moving visual patterns. Nature 300:523-525. CrossRef Medline

Akerman CJ, Smyth D, Thompson ID (2002) Visual experience before eyeopening and the development of the retinogeniculate pathway. Neuron 36:869-879. CrossRef Medline

Albrecht DG, Hamilton DB (1982) Striate cortex of monkey and cat: contrast response function. J Neurophysiol 48:217-237. CrossRef Medline

Angelucci A, Levitt JB, Lund JS (2002) Anatomical origins of the classical receptive field and modulatory surround field of single neurons in macaque visual cortical area V1. Prog Brain Res 136:373-388. CrossRef Medline

Angelucci A, Bijanzadeh M, Nurminen L, Federer F, Merlin S, Bressloff PC (2017) Circuits and mechanisms for surround modulation in visual cortex. Annu Rev Neurosci 40:425-451. CrossRef Medline

Barlow HB (1961) Possible principles underlying the transformation of sensory messages. In: Sensory communication (Rosenblith WA, ed), pp 217 234. Cambridge, MA: MIT.

Barlow HB (1972) Single units and sensation: a neuron doctrine for perceptual psychology? Perception 1:371-394. CrossRef Medline

Batschelet E (1981) Circular statistics in biology. New York: Academic.

Bauman LA, Bonds AB (1991) Inhibitory refinement of spatial frequency selectivity in single cells of the cat striate cortex. Vision Res 31:933-944. CrossRef Medline

Bell AJ, Sejnowski TJ (1997) The "independent components" of natural scenes are edge filters. Vision Res 37:3327-3338. CrossRef Medline

Berkes P, Orbán G, Lengyel M, Fiser J (2011) Spontaneous cortical activity reveals hallmarks of an optimal internal model of the environment. Science 331:83-87. CrossRef Medline

Blakemore C, Tobin EA (1972) Lateral inhibition between orientation detectors in the cat's visual cortex. Exp Brain Res 15:439-440. Medline

Bolz J, Gilbert CD (1986) Generation of end-inhibition in the visual cortex via interlaminar connections. Nature 320:362-365. CrossRef Medline

Bolz J, Gilbert CD (1989) The role of horizontal connections in generating long receptive fields in the cat visual cortex. Eur J Neurosci 1:263-268. CrossRef Medline

Brainard DH (1997) The Psychophysics Toolbox. Spat Vis 10:433-436. Medline

Britten KH, Heuer HW (1999) Spatial summation in the receptive fields of MT neurons. J Neurosci 19:5074-5084. Medline

Cang J, Niell CM, Liu X, Pfeiffenberger C, Feldheim DA, Stryker MP (2008) Selective disruption of one cartesian axis of cortical maps and receptive fields by deficiency in ephrin-as and structured activity. Neuron 57:511523. CrossRef Medline

Carandini M, Ferster D (2000) Membrane potential and firing rate in cat primary visual cortex. J Neurosci 20:470-484. Medline

Carandini M, Ringach DL (1997) Predictions of a recurrent model of orientation selectivity. Vision Res 37:3061-3071. CrossRef Medline

Carandini M, Heeger DJ (2011) Normalization as a canonical neural computation. Nat Rev Neurosci 13:51-62. CrossRef Medline 
Carandini M, Heeger DJ, Movshon JA (1997) Linearity and normalization in simple cells of the macaque primary visual cortex. J Neurosci 17:86218644. Medline

Cavanaugh JR, Bair W, Movshon JA (2002a) Nature and interaction of signals from the receptive field center and surround in macaque $\mathrm{V} 1$ neurons. J Neurophysiol 88:2530-2546. CrossRef Medline

Cavanaugh JR, Bair W, Movshon JA (2002b) Selectivity and spatial distribution of signals from the receptive field surround in macaque V1 neurons. J Neurophysiol 88:2547-2556. CrossRef Medline

Chapman B, Stryker MP (1993) Development of orientation selectivity in ferret visual cortex and effects of deprivation. J Neurosci 13:5251-5262. Medline

Chisum HJ, Mooser F, Fitzpatrick D (2003) Emergent properties of layer $2 / 3$ neurons reflect the collinear arrangement of horizontal connections in tree shrew visual cortex. J Neurosci 23:2947-2960. Medline

Clemens JM, Ritter NJ, Roy A, Miller JM, Van Hooser SD (2012) The laminar development of direction selectivity in ferret visual cortex. J Neurosci 32:18177-18185. CrossRef Medline

Das A, Gilbert CD (1999) Topography of contextual modulations mediated by short-range interactions in primary visual cortex. Nature 399:655661. CrossRef Medline

David SV, Vinje WE, Gallant JL (2004) Natural stimulus statistics alter the receptive field structure of V1 neurons. J Neurosci 24:6991-7006. CrossRef Medline

DeAngelis GC, Robson JG, Ohzawa I, Freeman RD (1992) Organization of suppression in receptive fields of neurons in cat visual cortex. J Neurophysiol 68:144-163. CrossRef Medline

DeAngelis GC, Ohzawa I, Freeman RD (1993) Spatiotemporal organization of simple-cell receptive fields in the cat's striate cortex. I. general characteristics and postnatal development. J Neurophysiol 69:1091-1117. CrossRef Medline

DeAngelis GC, Freeman RD, Ohzawa I (1994) Length and width tuning of neurons in the cat's primary visual cortex. J Neurophysiol 71:347-374. CrossRef Medline

Durack JC, Katz LC (1996) Development of horizontal projections in layer 2/3 of ferret visual cortex. Cereb Cortex 6:178-183. CrossRef Medline

Erisir A, Harris JL (2003) Decline of the critical period of visual plasticity is concurrent with the reduction of NR2B subunit of the synaptic NMDA receptor in layer 4. J Neurosci 23:5208-5218. Medline

Freeman DN, Marg E (1975) Visual acuity development coincides with the sensitive period in kittens. Nature 254:614-615. CrossRef Medline

Gilbert CD (1977) Laminar differences in receptive field properties of cells in cat primary visual cortex. J Physiol 268:391-421. CrossRef Medline

Gizzi MS, Katz E, Schumer RA, Movshon JA (1990) Selectivity for orientation and direction of motion of single neurons in cat striate and extrastriate visual cortex. J Neurophysiol 63:1529-1543. CrossRef Medline

Green DG, Powers MK, Banks MS (1980) Depth of focus, eye size and visual acuity. Vision Res 20:827-835. CrossRef Medline

Haider B, Krause MR, Duque A, Yu Y, Touryan J, Mazer JA, McCormick DA (2010) Synaptic and network mechanisms of sparse and reliable visual cortical activity during nonclassical receptive field stimulation. Neuron 65:107-121. CrossRef Medline

Hashemi-Nezhad M, Lyon DC (2012) Orientation tuning of the suppressive extraclassical surround depends on intrinsic organization of V1. Cereb Cortex 22:308-326. CrossRef Medline

Heeger DJ (1992) Normalization of cell responses in cat striate cortex. Vis Neurosci 9:181-197. CrossRef Medline

Heimel JA, Van Hooser SD, Nelson SB (2005) Laminar organization of response properties in primary visual cortex of the gray squirrel (Sciurus carolinensis). J Neurophysiol 94:3538-3554. CrossRef Medline

Heimel JA, Hartman RJ, Hermans JM, Levelt CN (2007) Screening mouse vision with intrinsic signal optical imaging. Eur J Neurosci 25:795-804. CrossRef Medline

Heuer HW, Britten KH (2002) Contrast dependence of response normalization in area MT of the rhesus macaque. J Neurophysiol 88:3398-3408. CrossRef Medline

Hubel DH, Wiesel TN (1965) Receptive fields and functional architecture in two nonstriate visual areas (18 and 19) of the cat. J Neurophysiol 28:229289. CrossRef Medline

Hubel DH, Wiesel TN (1968) Receptive fields and functional architecture of monkey striate cortex. J Physiol 195:215-243. CrossRef Medline
Jones HE, Grieve KL, Wang W, Sillito AM (2001) Surround suppression in primate V1. J Neurophysiol 86:2011-2028. CrossRef Medline

Khalil R, Levitt JB (2014) Developmental remodeling of corticocortical feedback circuits in ferret visual cortex. J Comp Neurol 522:3208-3228. CrossRef Medline

Koch E, Jin J, Alonso JM, Zaidi Q (2016) Functional implications of orientation maps in primary visual cortex. Nat Commun 7:13529. CrossRef Medline

Lauritzen TZ, Krukowski AE, Miller KD (2001) Local correlation-based circuitry can account for responses to multi-grating stimuli in a model of cat V1. J Neurophysiol 86:1803-1815. CrossRef Medline

Li B, Thompson JK, Duong T, Peterson MR, Freeman RD (2006a) Origins of cross-orientation suppression in the visual cortex. J Neurophysiol 96: 1755-1764. CrossRef Medline

Li DP, Hagan MA, Kiorpes L (2013) Linking structure and function: development of lateral spatial interactions in macaque monkeys. Vis Neurosci 30:263-270. CrossRef Medline

Li Y, Fitzpatrick D, White LE (2006b) The development of direction selectivity in ferret visual cortex requires early visual experience. Nat Neurosci 9:676-681. CrossRef Medline

Li Y, Van Hooser SD, Mazurek M, White LE, Fitzpatrick D (2008) Experience with moving visual stimuli drives the early development of cortical direction selectivity. Nature 456:952-956. CrossRef Medline

Mazurek M, Kager M, Van Hooser SD (2014) Robust quantification of orientation selectivity and direction selectivity. Front Neural Circuits 8:92. CrossRef Medline

Meister M, Wong RO, Baylor DA, Shatz CJ (1991) Synchronous bursts of action-potentials in ganglion cells of the developing mammalian retina. Science 252:939-943. CrossRef Medline

Mitchell DE (1988) The extent of visual recovery from early monocular or binocular visual deprivation in kittens. J Physiol 395:639-660. CrossRef Medline

Morrone MC, Burr DC, Maffei L (1982) Functional implications of crossorientation inhibition of cortical visual cells. I. neurophysiological evidence. Proc R Soc Lond B Biol Sci 216:335-354. CrossRef Medline

Morrone MC, Burr DC, Speed HD (1987) Cross-orientation inhibition in cat is GABA mediated. Exp Brain Res 67:635-644. Medline

Naka KI, Rushton WA (1966) S-potentials from colour units in the retina of fish (Cyprinidae). J Physiol 185:536-555. CrossRef Medline

Nurminen L, Angelucci A (2014) Multiple components of surround modulation in primary visual cortex: multiple neural circuits with multiple functions? Vision Res 104:47-56. CrossRef Medline

Ohshiro T, Angelaki DE, DeAngelis GC (2011) A normalization model of multisensory integration. Nat Neurosci 14:775-782. CrossRef Medline

Olsen SR, Bhandawat V, Wilson RI (2010) Divisive normalization in olfactory population codes. Neuron 66:287-299. CrossRef Medline

Olshausen BA, Field DJ (1996) Emergence of simple-cell receptive field properties by learning a sparse code for natural images. Nature 381:607609. CrossRef Medline

Pecka M, Han Y, Sader E, Mrsic-Flogel TD (2014) Experience-dependent specialization of receptive field surround for selective coding of natural scenes. Neuron 84:457-469. CrossRef Medline

Peirce JW (2007) The potential importance of saturating and supersaturating contrast response functions in visual cortex. J Vis 7(6):13, 1-10. CrossRef Medline

Pelli DG (1997) The VideoToolbox software for visual psychophysics: transforming numbers into movies. Spat Vis 10:437-442. Medline

Priebe NJ, Ferster D (2006) Mechanisms underlying cross-orientation suppression in cat visual cortex. Nat Neurosci 9:552-561. CrossRef Medline

Prusky GT, Douglas RM (2003) Developmental plasticity of mouse visual acuity. Eur J Neurosci 17:167-173. CrossRef Medline

Ranzato M, Boureau Y-L, LeCun Y (2007) Sparse feature learning for deep belief networks. Paper presented at Advances in Neural Information Processing Systems 20 (NIPS 2007), Vancouver, BC, Canada, December.

Reynolds JH, Heeger DJ (2009) The normalization model of attention. Neuron 61:168-185. CrossRef Medline

Reynolds JH, Chelazzi L, Desimone R (1999) Competitive mechanisms subserve attention in macaque areas V2 and V4. J Neurosci 19:1736-1753. Medline

Ringach DL, Bredfeldt CE, Shapley RM, Hawken MJ (2002) Suppression of neural responses to nonoptimal stimuli correlates with tuning selectivity in macaque V1. J Neurophysiol 87:1018-1027. CrossRef Medline 
Ritter NJ, Anderson NM, Van Hooser SD (2017) Visual stimulus speed does not influence the rapid emergence of direction selectivity in ferret visual cortex. J Neurosci 37:1557-1567. CrossRef Medline

Rowekamp RJ, Sharpee TO (2017) Cross-orientation suppression in visual area V2. Nat Commun 8:15739. CrossRef Medline

Roy A, Osik JJ, Ritter NJ, Wang S, Shaw JT, Fiser J, Van Hooser SD (2016) Optogenetic spatial and temporal control of cortical circuits on a columnar scale. J Neurophysiol 115:1043-1062. CrossRef Medline

Rubin DB, Van Hooser SD, Miller KD (2015) The stabilized supralinear network: a unifying circuit motif underlying multi-input integration in sensory cortex. Neuron 85:402-417. CrossRef Medline

Ruff DA, Alberts JJ, Cohen MR (2016) Relating normalization to neuronal populations across cortical areas. J Neurophysiol 116:1375-1386. CrossRef Medline

Ruthazer ES, Stryker MP (1996) The role of activity in the development of long-range horizontal connections in area 17 of the ferret. J Neurosci 16:7253-7269. Medline

Sato TK, Häusser M, Carandini M (2014) Distal connectivity causes summation and division across mouse visual cortex. Nat Neurosci 17:30-32. CrossRef Medline

Sato TK, Haider B, Häusser M, Carandini M (2016) An excitatory basis for divisive normalization in visual cortex. Nat Neurosci 19:568-570. CrossRef Medline

Sceniak MP, Ringach DL, Hawken MJ, Shapley R (1999) Contrast's effect on spatial summation by macaque V1 neurons. Nat Neurosci 2:733-739. CrossRef Medline

Self MW, Lorteije JA, Vangeneugden J, van Beest EH, Grigore ME, Levelt CN, Heimel JA, Roelfsema PR (2014) Orientation-tuned surround suppression in mouse visual cortex. J Neurosci 34:9290-9304. CrossRef Medline

Sengpiel F, Sen A, Blakemore C (1997) Characteristics of surround inhibition in cat area 17. Exp Brain Res 116:216-228. CrossRef Medline

Simoncelli EP, Heeger DJ (1998) A model of neuronal responses in visual area MT. Vision Res 38:743-761. CrossRef Medline

Smith GB, Sederberg A, Elyada YM, Van Hooser SD, Kaschube M, Fitzpatrick D (2015) The development of cortical circuits for motion discrimination. Nat Neurosci 18:252-261. CrossRef Medline

Somers DC, Nelson SB, Sur M (1995) An emergent model of orientation selectivity in cat visual cortical simple cells. J Neurosci 15:5448-5465. Medline

Tavazoie SF, Reid RC (2000) Diverse receptive fields in the lateral geniculate nucleus during thalamocortical development. Nat Neurosci 3:608-616. CrossRef Medline
Tolhurst DJ, Heeger DJ (1997) Comparison of contrast-normalization and threshold models of the responses of simple cells in cat striate cortex. Vis Neurosci 14:293-309. CrossRef Medline

Turrigiano GG, Nelson SB (2000) Hebb and homeostasis in neuronal plasticity. Curr Opin Neurobiol 10:358-364. CrossRef Medline

Van den Bergh G, Zhang B, Arckens L, Chino YM (2010) Receptive-field properties of V1 and V2 neurons in mice and macaque monkeys. J Comp Neurol 518:2051-2070. CrossRef Medline

van Hateren JH, van der Schaaf A (1998) Independent component filters of natural images compared with simple cells in primary visual cortex. Proc Biol Sci 265:359-366. CrossRef Medline

Van Hooser SD, Heimel JA, Chung S, Nelson SB (2006) Lack of patchy horizontal connectivity in primary visual cortex of a mammal without orientation maps. J Neurosci 26:7680-7692. CrossRef Medline

Van Hooser SD, Li Y, Christensson M, Smith GB, White LE, Fitzpatrick D (2012) Initial neighborhood biases and the quality of motion stimulation jointly influence the rapid emergence of direction preference in visual cortex. J Neurosci 32:7258-7266. CrossRef Medline

Vinje WE, Gallant JL (2002) Natural stimulation of the nonclassical receptive field increases information transmission efficiency in V1. J Neurosci 22:2904-2915. Medline

Wang BS, Sarnaik R, Cang J (2010) Critical period plasticity matches binocular orientation preference in the visual cortex. Neuron 65:246-256. CrossRef Medline

White LE, Fitzpatrick D (2007) Vision and cortical map development. Neuron 56:327-338. CrossRef Medline

White LE, Coppola DM, Fitzpatrick D (2001) The contribution of sensory experience to the maturation of orientation selectivity in ferret visual cortex. Nature 411:1049-1052. CrossRef Medline

Williams AL, Singh KD, Smith AT (2003) Surround modulation measured with functional MRI in the human visual cortex. J Neurophysiol 89:525533. CrossRef Medline

Zenger-Landolt B, Heeger DJ (2003) Response suppression in V1 agrees with psychophysics of surround masking. J Neurosci 23:6884-6893. Medline

Zhang B, Zheng J, Watanabe I, Maruko I, Bi H, Smith EL 3rd, Chino Y (2005) Delayed maturation of receptive field center/surround mechanisms in V2. Proc Natl Acad Sci U S A 102:5862-5867. CrossRef Medline

Zoccolan D, Cox DD, DiCarlo JJ (2005) Multiple object response normalization in monkey inferotemporal cortex. J Neurosci 25:8150-8164. CrossRef Medline 